OPEN ACCESS

Edited by:

Nikhil A. Thomas,

Dalhousie University, Canada

Reviewed by:

Eric Cox,

Ghent University, Belgium

Matthew S. Francis,

Umeå University, Sweden

*Correspondence:

Bertha González-Pedrajo

bpedrajo@ifc.unam.mx

Received: 21 June 2016 Accepted: 27 September 2016

Published: 21 October 2016

Citation

Gaytán MO, Martínez-Santos VI,

Soto $E$ and González-Pedrajo $B$ (2016) Type Three Secretion System in Attaching and Effacing Pathogens. Front. Cell. Infect. Microbiol. 6:129.

doi: 10.3389/fcimb.2016.00129

\section{Type Three Secretion System in Attaching and Effacing Pathogens}

\author{
Meztlli O. Gaytán, Verónica I. Martínez-Santos, Eduardo Soto and \\ Bertha González-Pedrajo *
}

Departamento de Genética Molecular, Instituto de Fisiología Celular, Universidad Nacional Autónoma de México, Ciudad de México, Mexico

Enteropathogenic Escherichia coli and enterohemorrhagic E. coli are diarrheagenic bacterial human pathogens that cause severe gastroenteritis. These enteric pathotypes, together with the mouse pathogen Citrobacter rodentium, belong to the family of attaching and effacing pathogens that form a distinctive histological lesion in the intestinal epithelium. The virulence of these bacteria depends on a type III secretion system (T3SS), which mediates the translocation of effector proteins from the bacterial cytosol into the infected cells. The core architecture of the T3SS consists of a multi-ring basal body embedded in the bacterial membranes, a periplasmic inner rod, a transmembrane export apparatus in the inner membrane, and cytosolic components including an ATPase complex and the C-ring. In addition, two distinct hollow appendages are assembled on the extracellular face of the basal body creating a channel for protein secretion: an approximately $23 \mathrm{~nm}$ needle, and a filament that extends up to $600 \mathrm{~nm}$. This filamentous structure allows these pathogens to get through the host cells mucus barrier. Upon contact with the target cell, a translocation pore is assembled in the host membrane through which the effector proteins are injected. Assembly of the T3SS is strictly regulated to ensure proper timing of substrate secretion. The different type III substrates coexist in the bacterial cytoplasm, and their hierarchical secretion is determined by specialized chaperones in coordination with two molecular switches and the so-called sorting platform. In this review, we present recent advances in the understanding of the T3SS in attaching and effacing pathogens.

Keywords: A/E pathogens, EPEC, EHEC, Citrobacter rodentium, locus of enterocyte effacement, type III secretion system, injectisome, secretion hierarchy

\section{INTRODUCTION}

The attaching and effacing (A/E) family of gastrointestinal bacterial pathogens induces a singular phenotype on host cells called the A/E lesion, characterized by the effacement of epithelial microvilli and the subsequent formation of actin-rich protruding structures known as pedestals right beneath the adherent bacteria, to which they remain intimately attached (Moon et al., 1983; Knutton et al., 1989; Nataro and Kaper, 1998). Members of this family include the human pathogens enteropathogenic Escherichia coli (EPEC) and enterohemorrhagic E. coli (EHEC), as well as the mouse pathogen Citrobacter rodentium, which is the representative organism used to understand the molecular basis of $\mathrm{A} / \mathrm{E}$ lesion formation in an infection animal model (Goosney et al., 2000; Collins et al., 2014). EPEC is considered one of the predominant causative agents of human diarrhea 
in developing countries, affecting principally infants aged 011 months, representing an important cause of mortality. It causes moderate to severe protracted diarrhea, accompanied by mild fever and sometimes vomiting (Nataro and Kaper, 1998; Kotloff et al., 2013). EPEC strains can also colonize rabbits (REPEC; rabbit-EPEC), mimicking to some extent the colonization process in humans, so this organism has been used as a model for studying EPEC infection (Milon et al., 1999; Zhu et al., 2006). EHEC is an emerging zoonotic pathogen that can cause acute gastroenteritis and hemorrhagic colitis in children younger than 5 years and the elderly (Boyce et al., 1995). It can also colonize ruminants, especially cattle, without being pathogenic, but rather using them as reservoirs ( $\mathrm{Su}$ and Brandt, 1995). In 1982, EHEC serotype O157:H7 was recognized as a human pathogen during two outbreaks associated with the ingestion of undercooked meat in the United States of America (Riley et al., 1983). In severe cases, due to the translocation of Shiga toxins (Stx1 and Stx2) across the gut, it can produce hemolytic uremic syndrome, which can lead to kidney failure and chronic post-infection sequelae or death (Frankel et al., 1998; Tarr et al., 2005; Spinale et al., 2013). Two main differences between these pathogens, besides the presence of Shiga toxins in EHEC, are the infectious dose and cellular tropism. While a dose between $10^{8}$ and $10^{10}$ bacteria is needed for EPEC to cause disease in adult volunteers (Donnenberg et al., 1993; Bieber et al., 1998), it has been estimated from EHEC found in contaminated food, that only 10-100 colony-forming units are sufficient for infection (Armstrong et al., 1996). With respect to tropism, EPEC colonizes the small intestine, specifically the duodenum, terminal ileum and Peyer's patches, while EHEC colonizes mainly the Peyer's patches and the large bowel (Phillips et al., 2000; Fitzhenry et al., 2002). Lastly, C. rodentium is a natural mouse pathogen that is genetically related to $E$. coli and forms A/E lesions in intestinal cells (Schauer and Falkow, 1993). Mice infected with C. rodentium develop transmissible murine colonic hyperplasia, a disease characterized by proliferation of epithelial colonic cells that can then turn into diarrhea (Mundy et al., 2005).

A/E lesion development occurs in three stages: (i) initial adherence, (ii) signal transduction, and (iii) intimate attachment (Donnenberg and Kaper, 1992). The first stage has been better characterized for EPEC, where it has been shown that bacteria adhere to host cells in a localized pattern through a type IV pilus (T4P) named BFP (bundle-forming pilus), which is also involved in bacterium-to-bacterium adherence (Girón et al., 1991). EHEC and C. rodentium also possess T4P, named HCP (hemorrhagic coli pilus) and CFC (colonization factor Citrobacter), respectively, that have been proposed to be involved in cell adherence and colonization (Mundy et al., 2003; Xicohtencatl-Cortes et al., 2007). Other fimbrial and afimbrial adhesins have been implicated in the initial adherence process such as intimin, flagella, and the E. coli common pilus, among others (Donnenberg and Kaper, 1991; Girón et al., 2002; Cleary et al., 2004; Rendón et al., 2007; Saldana et al., 2009). In the second stage, the bacteria interfere with a variety of signal transduction pathways in the host cell through the translocation of several virulence proteins, called effectors, via a highly conserved specialized protein-secretion apparatus called the type III secretion system (T3SS) (Garmendia et al., 2005). The number of translocated effectors varies from approximately 22 in EPEC and 29 in C. rodentium, to as many as 39 in certain EHEC strains (Tobe et al., 2006; Deng et al., 2010, 2012; Petty et al., 2010). Some changes induced by these proteins include modification of the host actin cytoskeleton (Campellone et al., 2004), failure of microtubule function (Hardwidge et al., 2005; Shaw et al., 2005; Tomson et al., 2005), inhibition of ion transport (Hodges et al., 2008), and disruption of epithelial barrier function (Viswanathan et al., 2009). In the third stage, the bacteria bind intimately to the host cell through an outer membrane protein called intimin, which functions as the ligand for the translocated receptor protein Tir inserted in the host cell membrane. The actin of microvilli surrounding attached bacteria is reabsorbed and the pedestal-like structure is completed leading to $\mathrm{A} / \mathrm{E}$ lesion formation and disease (Jerse and Kaper, 1991; Kenny and Finlay, 1997; Kenny et al., 1997b). This tight adhesion to the host's epithelia would provide an advantage to the pathogen for outcompeting normal microbiota (Vallance and Finlay, 2000).

As aforementioned, the T3SS plays a crucial role in A/E lesion formation and is essential to the virulence of these bacteria. In recent years, a notable progress has been achieved in our understanding of the T3SS machinery in A/E pathogens. This review aims to explore the assembly, structure and function of the T3SS in this important family of pathogens, highlighting its major differences with archetypical systems from Yersinia spp., Salmonella enterica, and Shigella flexneri. Therefore, to allow a straightforward comparison between homologous proteins, the unified nomenclature Sct (secretion and cellular translocation; Hueck, 1998) will also be used throughout the review.

\section{LOCUS OF ENTEROCYTE EFFACEMENT}

In $\mathrm{A} / \mathrm{E}$ pathogens the T3SS is encoded by a ca. $35 \mathrm{~kb}$ chromosomally located pathogenicity island (PAI) named the locus of enterocyte effacement (LEE) (Jarvis et al., 1995). The LEE genes are conserved in all $\mathrm{A} / \mathrm{E}$ pathogens, however it has been shown that, when introduced in a non-pathogenic E. coli K12 strain, the LEE of EPEC is sufficient for A/E lesion formation, whereas the LEE of EHEC is not (McDaniel and Kaper, 1997; Elliott et al., 1999b). The fact that the GC content (ca. 38\%) of these PAIs is significantly lower than that of the average of $E$. coli and C. rodentium genomes ( 50.8 and $54.6 \%$, respectively), reflects that they were acquired by horizontal gene transfer (Frankel et al., 1998; Deng et al., 2001; Schmidt and Hensel, 2004).

McDaniel and colleagues described the LEE for the first time in EPEC E2348/69 (McDaniel et al., 1995). It contains 41 genes organized in seven operons (LEE1 to LEE7) and four monocistronic units, as illustrated in Figure 1 (Elliott et al., 1998; Mellies et al., 1999; Sánchez-SanMartin et al., 2001; Barba et al., 2005; Yerushalmi et al., 2014). The LEE encodes all the structural components of the T3SS, seven of the effectors translocated through this system and their cognate chaperones, proteins involved in bacterial intimate adherence, and proteins that participate in secretion regulation and LEE expression (Table 1). All the genes encoded in the LEE of EPEC are 


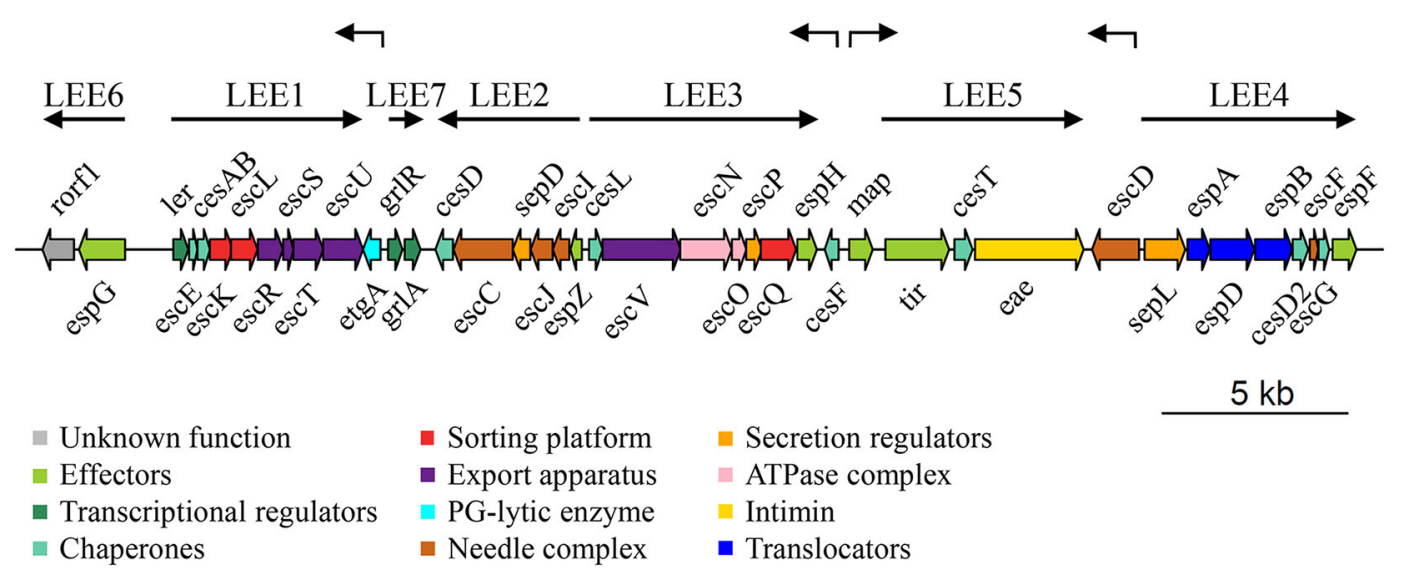

FIGURE 1 | Genetic structure of the LEE island of Escherichia coli E2348/69 0127:H6 strain (EPEC). Genes are depicted as filled arrows colored according to their proposed functional category (see enclosed box). The operon organization of the island (LEE1 to LEE7) is indicated by solid black arrows above the LEE genes, while individual transcriptional units (etgA, cesF, map, esc $D$ ) are denoted by broken arrows. Schematic representation is drawn at scale (scale bar $5 \mathrm{~kb})$. PG, peptidoglycan.

TABLE 1 | Functional organization of the LEE encoded T3SS components.

\begin{tabular}{|c|c|c|c|c|c|c|c|c|c|c|c|c|c|c|c|c|c|c|}
\hline \multicolumn{6}{|c|}{ Extracellular components } & \multirow{2}{*}{\multicolumn{2}{|c|}{$\begin{array}{l}\text { PG-lytic } \\
\text { enzyme }\end{array}$}} & \multirow[t]{2}{*}{ Adhesin } & \multicolumn{10}{|c|}{ Basal body } \\
\hline \multicolumn{3}{|c|}{ Translocation pore } & \multirow{2}{*}{\multicolumn{2}{|c|}{$\frac{\text { Filament }}{\text { EspA }}$}} & \multirow{2}{*}{$\frac{\text { Needle }}{\text { EscF }}$} & & & & \multicolumn{2}{|c|}{ IM ring } & \multirow{2}{*}{$\frac{\text { OM ring }}{\text { EscD }}$} & \multirow{2}{*}{\multicolumn{2}{|c|}{$\frac{\text { Inner rod }}{E s c l}$}} & \multicolumn{5}{|c|}{ Export apparatus } \\
\hline EspB & & EspD & & & & \multicolumn{2}{|c|}{ EtgA } & Intimin & EscD & EscJ & & & & EscR & EscS & EscT & $\mathrm{EscU}$ & EscV \\
\hline \multicolumn{19}{|c|}{ Cytoplasmic components } \\
\hline \multicolumn{3}{|c|}{ ATPase complex } & & & \multirow{2}{*}{\multicolumn{3}{|c|}{ Secretion regulation }} & \multirow{2}{*}{\multicolumn{3}{|c|}{$\begin{array}{l}\text { Transcriptional } \\
\text { regulators }\end{array}$}} & \multicolumn{8}{|c|}{ Chaperones } \\
\hline \multicolumn{5}{|c|}{ Sorting platform } & & & & & & & \multicolumn{2}{|c|}{ Early substrates } & \multicolumn{3}{|c|}{ Middle substrates } & \multicolumn{3}{|c|}{ Late substrates } \\
\hline $\mathrm{EscN}$ & EscO & EscL & EscQ & EscK & EscP & SepL & SepD & Ler & GrlA & GrIR & EscE & $c G$ & CesAB & CesD & CesD2 & CesT & CesF & CesL \\
\hline
\end{tabular}

Cytoplasmic components

\begin{tabular}{|c|c|c|c|c|c|c|}
\hline \multicolumn{7}{|c|}{ LEE-encoded effectors } \\
\hline EspG & EspZ & EspH & Map & Tir & EspF & EspB \\
\hline
\end{tabular}

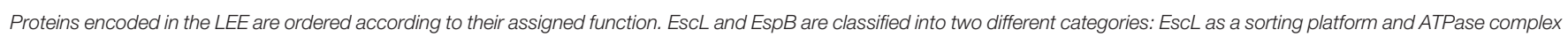
component, and EspB as a translocator and effector.

present in the LEE of EHEC in the same order, and have a high degree of conservation showing an average identity of $94 \%$ at the nucleotide level (Perna et al., 1998). The LEE PAI is also conserved in $C$. rodentium, but with some differences with respect to that of EPEC and EHEC. The LEE islands of EPEC and EHEC are inserted into the selenocysteine tRNA locus; while the C. rodentium $\mathrm{LEE}$ is inserted in a different chromosomal location flanked by an IS element followed by an operon encoding an $\mathrm{ABC}$ transport system and plasmid sequences. Furthermore, the LEE6 operon of $C$. rodentium, containing the rorf1 and esp $G$ genes, is positioned at the opposite end of the LEE with respect to EPEC and EHEC (Deng et al., 2001; Petty et al., 2010).
The proper expression of the LEE is a complex process that depends on several factors, such as environmental conditions, quorum sensing, and transcriptional as well as posttranscriptional regulation (Connolly et al., 2015). The LEE encodes its own transcriptional regulators, named Ler, GrlA, and GrlR (Mellies et al., 1999; Deng et al., 2004). Ler is a $15-\mathrm{kDa}$ protein encoded by the first gene of the LEE1 operon that acts as the central regulator of LEE gene expression (Mellies et al., 1999). This protein belongs to the H-NS-like protein family whose main representative, $\mathrm{H}-\mathrm{NS}$, negatively regulates the expression of several horizontally acquired genetic elements, including the LEE (Bustamante et al., 2001; Umanski et al., 2002; Dorman, 2004). Ler counteracts the repression exerted by H-NS and thus 
is essential for the expression of the LEE (Bustamante et al., 2001; Winardhi et al., 2014). Interestingly, Ler also acts as a negative regulator of its own expression (Berdichevsky et al., 2005; Bhat et al., 2014). In addition, GrlA and GrlR, encoded in the bicistronic LEE7 operon, positively and negatively regulate Ler expression (Deng et al., 2004; Huang and Syu, 2008). GrlA has been shown to activate LEE gene expression through its direct binding to the LEE1 promoter (Jiménez et al., 2010), and Ler controls the expression of the LEE7 operon, thus forming a positive regulatory loop (Barba et al., 2005). On the other hand, GrlR represses LEE gene expression, although the mechanism of repression is still unknown. GrlR has been demonstrated to interact directly with GrlA (Creasey et al., 2003b; Padavannil et al., 2013); therefore, it was proposed that GrlR represses LEE transcription by sequestering GrlA, avoiding its binding to the LEE1 promoter and thus repressing ler expression (Huang and Syu, 2008).

Besides these three transcriptional regulators, a fourth LEEencoded protein has been proposed to modulate LEE expression in EHEC (Sun et al., 2016). The Mpc (multiple point controller) protein, also known as CesL (previously Orf12 or L0036), was shown to interact with Ler (Tsai et al., 2006; Younis et al., 2010). When Mpc is overexpressed, it sequesters Ler impeding its function and leading to the repression of the LEE encoded genes (Tsai et al., 2006). Furthermore, in typical EPEC strains containing the EAF (EPEC adherence factor) plasmid, LEE expression is also positively regulated by PerC, a transcriptional regulator encoded by the per $A B C$ plasmid-located operon (Gómez-Duarte and Kaper, 1995; Tobe et al., 1996). EHEC possess three PerC homologous proteins named PchA, PchB and PchC (Iyoda and Watanabe, 2004), while there is no known PerC homolog in C. rodentium.

To illustrate the complexity of the regulatory networks that govern LEE expression suffice it to mention that several global transcriptional regulators are involved in LEE regulation, such as BipA, Cpx, Fis, GadE, Hha, H-NS, H-NST, IHF, RgdR, RpoN, SspA, FusK/R, EutR, LeuO, SdiA, KdpE, QseA, QseC, QseD, QseE, RcsB, RegA, and GlmY/GlmZ. Besides, LEE expression is also regulated at the post-transcriptional level by ClpXP, CsrA, DegP, DsrA, Hfq, RNaseE, and RpoS, reviewed in Deane et al. (2010), Yang et al. (2010) Levine et al. (2014) and Franzin and Sircili (2015).

\section{STRUCTURE OF THE TYPE III SECRETION SYSTEM}

The T3SS or injectisome is a complex nanomolecular machine of about 3.5 MDa consisting of more than 20 proteins. The injectisome global architecture is conserved among different bacterial species and resembles that of the evolutionarily related flagellar system (Hueck, 1998; Erhardt et al., 2010b; Abby and Rocha, 2012). It is composed of a syringe shaped-structure protruding above the bacterial surface with a central channel of $2-3 \mathrm{~nm}$ in diameter, and three ring structures embedded in the inner and outer bacterial membranes, connected through a periplasmic inner rod (Hueck, 1998; Burkinshaw and Strynadka,
2014; Notti and Stebbins, 2016). Although, the core architecture of this so-called needle complex is highly similar in bacteria analyzed so far, the supramolecular structure of the EPEC and EHEC T3SS shows an extracellular filament assembled on top of the needle (see below; Ebel et al., 1998; Knutton et al., 1998; Daniell et al., 2001b; Sekiya et al., 2001). Overall, the components of the T3SS can be grouped according to the substructures they form, from outside in: extracellular appendages, basal body and cytoplasmic components. A schematic representation of the T3SS in A/E pathogens as well as several solved protein structures are depicted in Figure 2.

\section{Extracellular Appendages The Needle}

The needle is a superhelical hollow structure comprised of multiple copies of the EscF protein (Wilson et al., 2001), which is essential for the secretion of all T3 substrates and hence for virulence (Deng et al., 2004). EscF associates with the membrane ring proteins EscC, EscD, and EscJ (Ogino et al., 2006), as well as with the filament protein EspA (Wilson et al., 2001), forming a continuous channel that connects the bacterial cytoplasm with the host cell (Figure 2). It also associates in the cytoplasm with two chaperones, EscE and EscG that prevent its premature polymerization and are essential for its assembly (Sal-Man et al., 2013).

In EPEC, the needle is $23 \mathrm{~nm}$ in length and 8-9 $\mathrm{nm}$ in width (Sekiya et al., 2001; Ogino et al., 2006; Monjarás Feria et al., 2012). Although, the inner diameter of the needle central conduit in $\mathrm{A} / \mathrm{E}$ pathogens has not been determined, in other T3S systems it ranges from about 1.3 to $2.5 \mathrm{~nm}$ (Blocker et al., 2001; Fujii et al., 2012; Loquet et al., 2012). The size of this channel is not wide enough to accommodate folded proteins; therefore, effectors should be unfolded prior to transport through to the T3SS (Feldman et al., 2002; Akeda and Galán, 2005; Fujii et al., 2012). This hypothesis was demonstrated by the fusion of a stable protein, or bulky proteins containing a knotted motif, to the C-terminal ends of T3 substrates. The fusion proteins were trapped inside the needle, blocking further secretion and allowing its co-purification with isolated T3S needle complexes (Dohlich et al., 2014; Radics et al., 2014). Visualization of the trapped recombinant substrates by cryo-EM provided direct evidence for the passage of unfolded proteins through this structure (Radics et al., 2014).

The EPEC needle structure is one of the smallest characterized, compared to those of S. enterica $(25-80 \mathrm{~nm})$ (Kubori et al., 1998; Kimbrough and Miller, 2000; Marlovits et al., 2006), S. flexneri (45-50 nm) (Tamano et al., 2000), Y. pestis $(41 \mathrm{~nm})$, and Y. enterocolitica $(58 \mathrm{~nm})$ (Journet et al., 2003). The needle length is strictly regulated by and correlates with the size of a family of proteins named type III secretion substrate specificity switch (T3S4) proteins (Journet et al., 2003; Büttner, 2012). In A/E pathogens, the EscP protein belongs to the T3S4 protein family, and in EPEC it was demonstrated to directly interact with EscF (Monjarás Feria et al., 2012). This interaction is important for needle length regulation in a process that will be discussed below. Furthermore, in other bacteria it has been proposed that the needle plays an active role in mammalian cell 

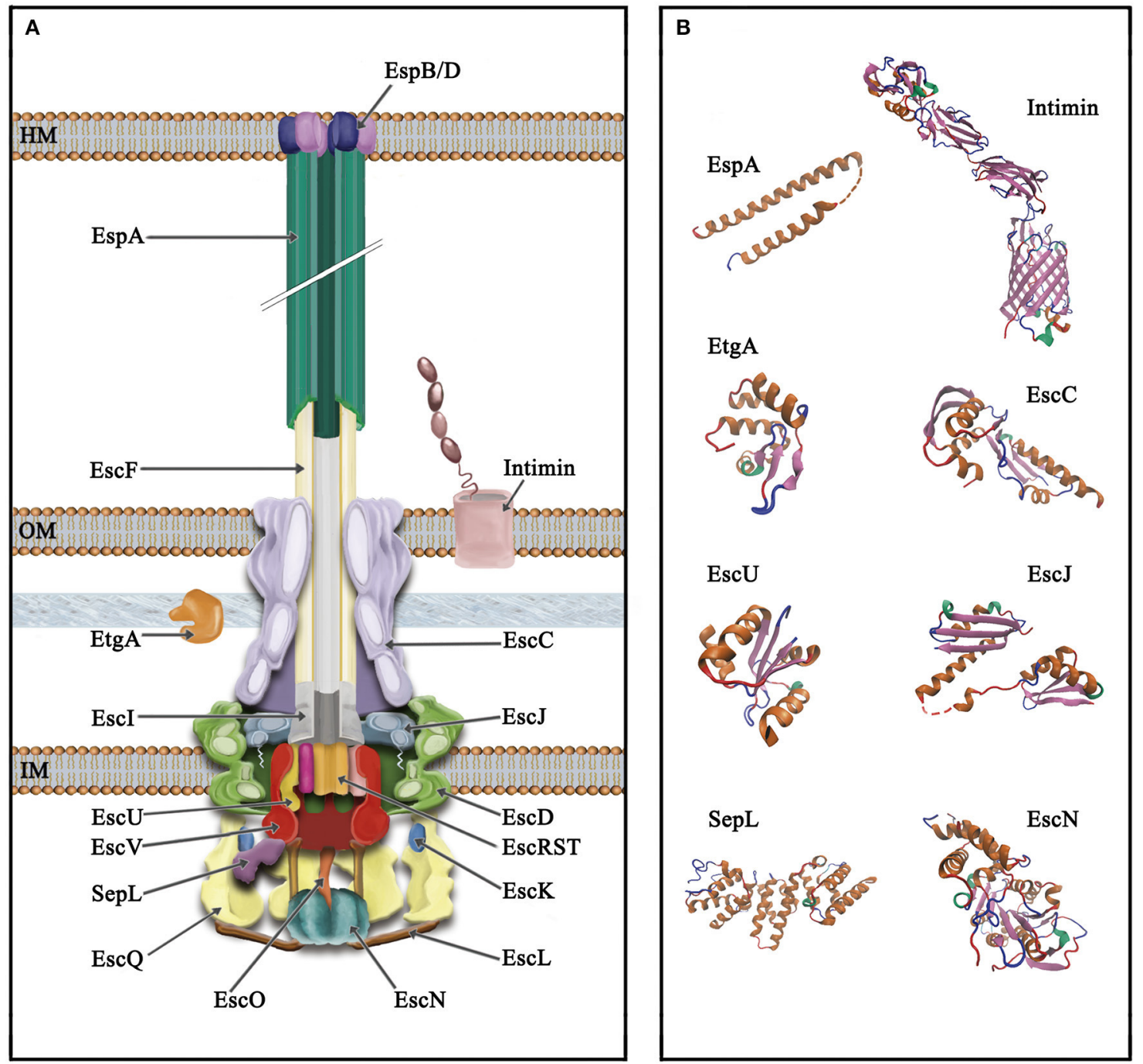

FIGURE 2 | Schematic representation of the type III secretion system of A/E pathogens. (A) The T3SS is divided into three main parts, from top to bottom (i) extracellular appendages: translocation pore (inserted into the host membrane, HM), filament and needle; (ii) basal body: consisting of three membrane rings that span the inner and outer membrane (IM and OM, respectively) connected through a periplasmic inner rod. The IM rings house the export apparatus components; (iii) cytoplasmic components: the C-ring, the ATPase complex and the gatekeeper protein. The outer membrane protein intimin and the PG Iytic enzyme EtgA are also illustrated. (B) Solved protein structures of the depicted T3SS components. Protein Data Bank (PDB) accession numbers: SepL, 5C9E; EscN, 2OBM; cytoplasmic C-terminal domain of EscU, 3BZL; periplasmic domain of EscC, 3GR5; EtgA, 4XP8; periplasmic domain of EscJ, 1YJ7; the EspA structure was obtained from that of the CesAB/EspA complex, 1XOU, chain A; transmembrane beta-domain of intimin, 4E1S and its C-terminal domain, 1F00. Protein structures are displayed as ribbon diagrams and were colored according to their secondary structure.

sensing and substrate secretion regulation (Kenjale et al., 2005; Torruellas et al., 2005); however, no direct evidence about this process has been reported in $\mathrm{A} / \mathrm{E}$ pathogens.

Remarkably, the number of needle complexes in EPEC has been estimated to be 12 per cell, based on the observed EspA filaments (Daniell et al., 2001b; Wilson et al., 2001), which is fewer than the number seen in Salmonella (10-100; Kubori et al., 1998) and Yersinia (30-100; Hoiczyk and Blobel, 2001).

\section{The Filament}

The filament is an extracellular appendage found in the T3S systems of $\mathrm{A} / \mathrm{E}$ pathogens (also present in Bordetella spp.) that functions as an adaptor between the needle and the translocation pore formed in the host cell membrane (Figure 2; Knutton et al., 1998; Ide et al., 2001; Medhekar et al., 2009). In A/E pathogens, it is assembled by the polymerization of multiple subunits of the EspA protein with a helical symmetry of 5.6 subunits per turn (Knutton et al., 1998; Daniell et al., 2003; Wang et al., 2006), forming a hollow structure of $12 \mathrm{~nm}$ in width that allows the passage of substrates through a $2.5 \mathrm{~nm}$ central channel (Daniell et al., 2001b, 2003; Crepin et al., 2005b). Unlike the needle, the EspA filament has a variable length that can reach more than $600 \mathrm{~nm}$, which seems to be dependent on the availability of EspA subunits given that it can be enlarged by increasing the amount of 
EspA in the cytoplasm (Sekiya et al., 2001; Crepin et al., 2005b). The average length of the filament is ca. $90 \mathrm{~nm}$ and it elongates by addition of EspA subunits at the tip of the structure (Daniell et al., 2003; Crepin et al., 2005b).

The EspA protein has a coiled-coil domain at its C-terminal region that is required for subunit polymerization and assembly of the filament (Delahay et al., 1999). Since this protein undergoes spontaneous polymerization, it requires the assistance of chaperone proteins in the cytoplasm. CesAB was the first EspA chaperone to be described (Creasey et al., 2003c). The crystal structure of the CesAB-EspA complex showed that the coiledcoil domain of EspA is also the one involved in the interaction with CesAB, thus revealing the mechanism that prevents EspA premature oligomerization (Yip et al., 2005a). Besides CesAB, EspA has a second chaperone named CesA2 (formerly Orf29, renamed EscG in EPEC) that assists EspA stabilization in the cytoplasm (Su et al., 2008). In EHEC it has also been reported that EspA binds to EscL, a component of the ATPase complex, and that this interaction is required to preserve EspA stability, although not via a chaperoning mechanism (Ku et al., 2009). EspA can also directly bind to EscF and EspB, forming a continuous channel from the bacterial cytoplasm to the host cell cytosol (Hartland et al., 2000; Daniell et al., 2001b).

Apart from its role as a translocation conduit, and similarly to the needle, the EspA filament has been proposed to participate in sensing the presence of mammalian cells, and there is evidence that involves this structure in adhesion to epithelial cells and biofilm formation (Ebel et al., 1998; Knutton et al., 1998; Cleary et al., 2004; Moreira et al., 2006). However, the EspA filaments are not present over the entire course of infection; once the intimate attachment has been established, they are eliminated and so are absent from the mature $\mathrm{A} / \mathrm{E}$ lesion. Indeed, it has been reported that expression of the espA gene, and thus the presence of EspA filaments, is downregulated after $6 \mathrm{~h}$ of infection (Knutton et al., 1998; Dahan et al., 2004).

\section{The Translocation Pore}

The translocation pore is a protein complex formed by the hetero-oligomerization of EspB and EspD subunits. These proteins interact with each other and insert into the host membrane, forming a channel that allows the direct translocation of effectors from the bacteria to the host cell cytoplasm (Figure 2; Ide et al., 2001). The EspB and EspD proteins are predicted to have one and two transmembrane domains, respectively, involved in their membrane anchoring (Delahay and Frankel, 2002; Dasanayake et al., 2011). It has been shown that they can insert into erythrocyte membranes causing red blood cells (RBCs) hemolysis (Warawa et al., 1999). Moreover, both of these hydrophobic translocators interact with the hydrophilic translocator EspA, forming the so-called translocon (Hartland et al., 2000; Luo and Donnenberg, 2011). Mutants in any of the translocon components are still able to secrete proteins to the medium, but fail to translocate them to the host cell, thus impairing adhesion, A/E lesion formation and virulence (Lai et al., 1997; Kresse et al., 1999; Deng et al., 2004).

Analysis with low resolution atomic force microscopy showed that the pores formed by EspB and EspD in diffusely adhering
EPEC (DA-EPEC) are composed of six to eight subunits with a minimal pore size of 3-5 nm (Ide et al., 2001). In addition, EspD, which is able to interact with itself through a C-terminal coiledcoil domain (Daniell et al., 2001a), spontaneously incorporates into unilamellar vesicles, forming a pore with an inner diameter of $2.5 \mathrm{~nm}$ and a molecular mass of $280-320 \mathrm{kDa}$, which would consist of six to seven subunits (Chatterjee et al., 2015). In agreement with this, analysis of RBC membranes during EPECmediated hemolysis showed that EspD was the only bacterial protein membrane-associated, suggesting it plays a dominant role in pore formation. In contrast, EspB seems to have a secondary role in pore formation since a $\Delta \operatorname{esp} B$ mutant caused only a slight reduction in hemolysis (Shaw et al., 2001).

Although, significant advances have been made in determining the components that form the translocation pore, and to a lesser extent, its stoichiometry, little is known about their topology when inserted into the host membrane. For $P$. aeruginosa translocator proteins PopB and PopD (EspD and EspB homologs, respectively), it has been shown that PopB is inserted into the host membrane with both the $\mathrm{N}$ - and C-terminus facing the outer leaflet of host plasma membrane. Likewise, the C-terminus of PopD is located toward the extracellular milieu, where it docks to the needle tip formed by $\mathrm{PcrV}$ (EspA in A/E pathogens), while its $\mathrm{N}$-terminus is facing the host cytoplasm (Discola et al., 2014; Armentrout and Rietsch, 2016). The proposed membrane orientation of PopD differs from that reported for EspB in EPEC where, by introducing sequences recognized by a host kinase, it was demonstrated that the C-terminal domain of EspB is localized in the host cytoplasm while the N-terminal domain remains extracellular (Luo and Donnenberg, 2011).

Additionally, it has been reported that cholesterol membrane content plays an important role in EPEC and EHEC adherence, protein translocation and pedestal formation (Hayward et al., 2005; Riff et al., 2005). In fact, it was shown that the EspD homologs in Salmonella (SipB) and Shigella (IpaB) bind with high affinity to cholesterol, which is required for efficient delivery of effectors into host cells (Hayward et al., 2005). However, even though it was initially reported that EspD inserts into Triton X-100 resistant membrane domains (Wachter et al., 1999), and binds to vesicles with a lipid composition that resembles that of the eukaryotic outer leaflet of the membrane, it was later demonstrated that cholesterol is not required for EspD binding or pore formation; instead, addition of anionic lipids such as phosphatidylserine or phosphaditylglycerol induces pore formation of EspD in unilamellar vesicles (Chatterjee et al., 2015). It is possible that cholesterol is necessary for the function of effectors associated with the host membrane rather than for the translocon assembly per se (Allen-Vercoe et al., 2006; Chatterjee et al., 2015); however, this issue remains a matter of debate. Recently, the translocon pore-forming activity was demonstrated to be regulated by the serine protease autotransporters EspC and EspP in EPEC and EHEC, respectively (Guignot et al., 2015). EspC degrades EspA and EspD after host cell contact, regulating the translocation pore forming activity, which in turn downregulates the cytotoxicity induced by EPEC (Guignot et al., 2015). This is in agreement with previous findings showing that 
EspC interacts with EspA (Vidal and Navarro-García, 2008) and that a mutant defective in the EspC ortholog in C. rodentium displayed increased virulence in an in vivo infection model (Vijayakumar et al., 2014).

Besides its role as a pore-forming component, EspB is as well translocated into host cells, where it binds to myosin, inhibiting its interaction with actin and contributing to microvilli effacement and EPEC phagocytosis inhibition (Taylor et al., 1998; Wolff et al., 1998; Iizumi et al., 2007). It has also been demonstrated to bind and recruit $\alpha$-catenin at the EHEC adherence site, helping to the development of the $\mathrm{A} / \mathrm{E}$ lesion (Kodama et al., 2002). EspD and EspB are assisted in the bacterial cytoplasm by three chaperones CesD, CesD2, and CesAB that maintain them in an unfolded state and prevent their premature oligomerization (Wainwright and Kaper, 1998; Creasey et al., 2003c; Neves et al., 2003).

\section{Basal Body}

The basal body consists of three membrane rings connected through a periplasmic inner rod. The proteins EscD and EscJ form two concentric rings in the inner membrane (IM) and the EscC protein forms the outer membrane (OM) ring (Figure 2). The estimated values for the external widths of the OM and IM rings are $16.7 \pm 1.9 \mathrm{~nm}$ and $18.1 \pm 2.5 \mathrm{~nm}$, respectively (Sekiya et al., 2001). These ring dimensions are similar to those reported for Shigella (15 $\pm 1.3 \mathrm{~nm}$ and $26.1 \pm 1.3 \mathrm{~nm}$; Tamano et al., 2000), and Y. enterocolitica (12 and $18 \mathrm{~nm}$; Kudryashev et al., 2013). The height of the basal body, $31.4 \pm 4.3 \mathrm{~nm}$ in EPEC and $31.6 \pm$ $0.3 \mathrm{~nm}$ in Shigella, is also quite similar and presumably sufficient to traverse the bacterial membranes and the peptidoglycan layer (Sekiya et al., 2001).

EscD possesses a predicted transmembrane domain (amino acids $120-141$ ) as well as seven predicted myristoylation sites (Kresse et al., 1998; Ogino et al., 2006). Like its Yersinia homolog YscD, it contains a cytoplasmic forkhead associated (FHA) domain, which mediates phosphoprotein-recognition, and at least one putative phospholipid-binding domain (BON; bacterial OsmY and nodulation domain) in its periplasmic portion (Pallen et al., 2002, 2005; Gamez et al., 2012). The FHA domain of $Y$. pestis YscD is essential for T3SS formation and that of $S$. flexneri MxiG interacts with phosphorylated Spa33 (the EscQ homolog; Ross and Plano, 2011; Barison et al., 2012); however, its role in EscD function remains to be determined. The EscD protein associates with the $\mathrm{OM}$ ring protein $\mathrm{EscC}$ and the needle component EscF; yet, no direct interaction with the IM ring protein EscJ has been demonstrated (Creasey et al., 2003b; Ogino et al., 2006). Nevertheless, by analogy to its homologs in other systems (Kimbrough and Miller, 2000; Blocker et al., 2001; Schraidt et al., 2010), EscD is believed to form the outermost IM ring that surrounds the EscJ ring. EscJ is produced as a preprotein and is presumed to be translocated to the periplasm in a Sec-dependent manner (Crepin et al., 2005a). Crystal packing analysis of the solved structure of this protein showed that it forms a 24 subunit ring of $18 \mathrm{~nm}$ width and $5.2 \mathrm{~nm}$ height that fits the dimensions of the IM rings observed by transmission electron microscopy (TEM) (Sekiya et al., 2001; Yip et al., 2005b). Unlike its homologs, EscJ does not possess a transmembrane helix in its C-terminal domain; instead, it is anchored to the outer leaflet of the IM through an N-terminal lipid modification site (Figure 3A). Hence, EscJ forms a periplasmic ring positioned on top of the IM rather than within it (Crepin et al., 2005a; Yip et al., 2005b). The EscJ flagellar homolog FliF, also selfassembles in an annular structure in the IM forming the MS (membrane and supramembrane) ring of the flagellar T3SS (Ueno et al., 1992; Bergeron, 2016). In contrast to its virulence counterparts, FliF contains two transmembrane helices and a C-terminal cytoplasmic domain that directly interacts with the C-ring component FliG (Marykwas et al., 1996; Levenson et al., 2012).

The OM ring component EscC is essential for T3 secretion and needle complex formation (Gauthier et al., 2003; Deng et al., 2004; Ogino et al., 2006). EscC belongs to the secretin family of proteins that function as channels for secretion of bacterial proteins across the $\mathrm{OM}$ in several secretion systems. They consist of two major domains: an N-terminal periplasmic region and a highly conserved C-terminal region embedded in the outer membrane (Genin and Boucher, 1994). EscC possesses a signal sequence that is cleaved after its Sec-dependent export across the IM. In many T3S systems, the oligomerization of the secretin and its insertion in the $\mathrm{OM}$ is promoted by a lipoprotein called pilotin (Crago and Koronakis, 1998; Schuch and Maurelli, 2001; Burghout et al., 2004). However, this protein has not been identified in the T3SS of A/E pathogens and, in agreement, the $\mathrm{C}$-terminal pilotin binding domain is absent in the $\mathrm{EscC}$ protein of EPEC, as shown in Figure 3B. In this regard, it has been reported that the proper OM localization of EscC requires the aid of other T3 apparatus components (Gauthier et al., 2003).

The crystal structure of the periplasmic region of the secretin EscC (residues 21-174) revealed a modular architecture of two small domains connected by a linker region that has a similar fold to the IM proteins EscJ and PrgH (EscD homolog in Salmonella). This suggests that the conserved fold might provide a common ring assembly motif for oligomerization of OM and IM rings in T3S systems (Spreter et al., 2009). EscC oligomerizes into a $17 \mathrm{~nm}$ diameter ring (Ogino et al., 2006). The cryoEM of InvG (EscC homolog in Salmonella) suggests that the OM ring is composed of 15 subunits (Schraidt and Marlovits, 2011; Bergeron et al., 2013), while the cryo-EM and scanningTEM analysis of Yersinia YscC and Shigella MxiD indicate that these secretins are composed of 12 subunits (Hodgkinson et al., 2009; Kowal et al., 2013). In the case of EscC, Spreter and colleagues built 12- and 14-subunit ring models, which were then docked to the cryo-EM maps of the S. enterica T3SS basal body (Marlovits et al., 2004). Although both models fitted the density maps, there is currently more evidence favoring the 12-mer model (Spreter et al., 2009), anyhow the OM ring stoichiometry in the T3SS of $\mathrm{A} / \mathrm{E}$ pathogens remains to be demonstrated.

Regarding EscC protein interactions it has been demonstrated that it associates with the IM ring EscD (Creasey et al., 2003b; Ogino et al., 2006) and with injectisome axial components like the inner rod EscI and the needle EscF (Creasey et al., 2003b; Sal-Man et al., 2012b). In addition, it has been shown that EscC interacts with EscO (previously EscA; Sal-Man et al., 2012a), an 


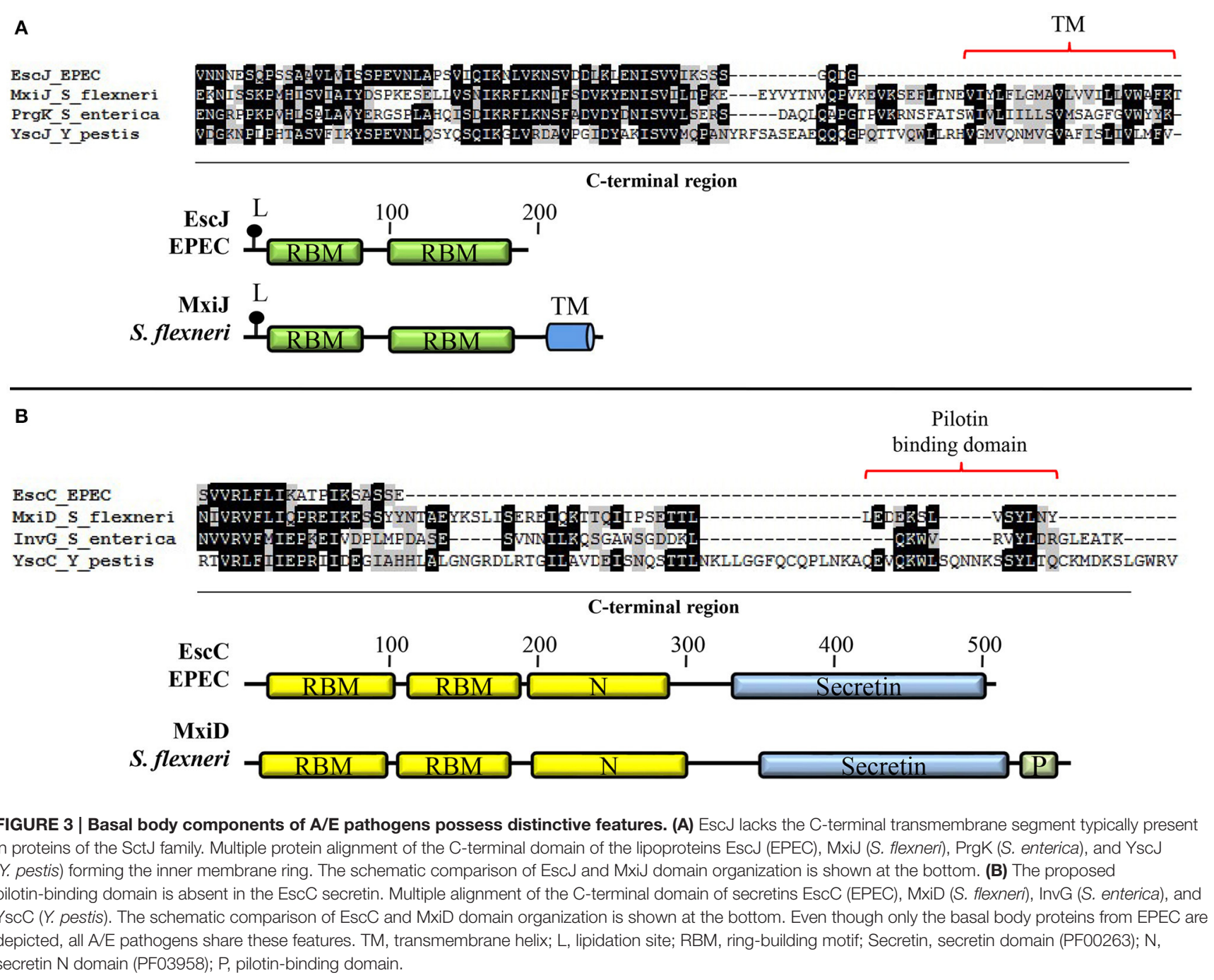

ATPase complex component (Romo-Castillo et al., 2014), yet the functional relevance of this interaction remains to be established.

It is presumed that the OM and IM rings are connected through a periplasmic inner rod formed by the oligomerization of the EscI protein (Pallen et al., 2005; Sal-Man et al., 2012b). When visualized by EM the inner rod appeared to have a small ring-like structure at the base (10 $\mathrm{nm}$ in diameter), and a stem portion of $9 \mathrm{~nm}$ in width which is identical to the diameter of the needle; the entire length of the rod is approximately $20 \mathrm{~nm}$ (Ogino et al., 2006). In contrast, a recent study of the inner rod in $S$. enterica showed that this structure is made of only one helical turn composed of six PrgJ subunits (Zilkenat et al., 2016).

Additionally, the EscI homologs in Yersinia and Salmonella have been shown to be involved in the process that regulates T3 substrate secretion (Marlovits et al., 2006; Wood et al., 2008; Lefebre and Galán, 2014). In agreement, in EPEC it has been demonstrated that EscI interacts with EscU (Sal-Man et al., 2012b) and with EscP (Monjarás Feria et al., 2012), components involved in substrate secretion regulation as will be discussed below.
Injectisome assembly faces a physical barrier; it must traverse the peptidoglycan (PG) layer. In EPEC this task is accomplished by the use of a specialized PG degrading enzyme named EtgA (Pallen et al., 2005) that localizes to the periplasm to exert its PG lytic activity and which is required for efficient T3SS assembly (García-Gómez et al., 2011). The recently solved structure of EtgA disclosed similarities in its active site with both lytic transglycosylases and lysozyme (Burkinshaw et al., 2015a). This enzyme has been shown to interact directly with the inner rod subunit EscI (Creasey et al., 2003b; Burkinshaw et al., 2015a). Moreover, the enzymatic activity of EtgA is enhanced in the presence of EscI, suggesting that this interaction not only spatially restricts the activity of EtgA but also stimulates it (Burkinshaw et al., 2015a).

\section{Export Apparatus}

One of the most conserved components of the injectisome is the export apparatus. This membrane-embedded complex is essential for T3S function and, in A/E pathogens, is built of five different proteins: EscR, EscS, EscT, EscU, and EscV (EscRSTUV; 
Deng et al., 2004; Diepold and Wagner, 2014; Portaliou et al., 2016). These five polytopic proteins, which have been annotated by sequence comparison to its homologs in Yersinia (Elliott et al., 1998; Pallen et al., 2005), are presumed to assemble in a patch of the cytoplasmic membrane enclosed by the two inner membrane rings of the basal body (Figure 2; Yip et al., 2005b; Moraes et al., 2008; Wagner et al., 2010a).

Apart from its requirement for $\mathrm{T} 3$ protein secretion, little is known about the integral membrane components of the export apparatus, although considerable information has also been obtained from the homologous proteins in the flagellar T3SS (Minamino, 2014). EscU and EscV, as well as their respective homologs, which possess large cytoplasmic domains, are the most studied components of this protein complex. EscU belongs to the YscU/FlhB family of proteins, whose members are predicted to have two major domains connected through a conserved flexible linker: an N-terminal domain of ca. 200 amino acids that contains four predicted transmembrane regions, and a cytoplasmic C-terminal domain of ca. 100 amino acids that undergoes autocleavage in its NPTH amino acid motif. This autoproteolytic event between the asparagine and proline residues has been proposed to participate in substrate specificity switching (discussed below; Lavander et al., 2002; Fraser et al., 2003; Ferris et al., 2005; Sorg et al., 2007; Deane et al., 2008a; Zarivach et al., 2008; Björnfot et al., 2009; Lountos et al., 2009; Smith et al., 2009; Wiesand et al., 2009; Lorenz and Büttner, 2011; Thomassin et al., 2011). EscU interacts directly with EscP and EscI, and both interactions have also been implicated in the switching event (Zarivach et al., 2008; Thomassin et al., 2011; Monjarás Feria et al., 2012; Sal-Man et al., 2012b).

EscV, the major constituent of the T3 export apparatus, is also composed of two main domains: an $\mathrm{N}$-terminal region with eight transmembrane helices and a C-terminal cytoplasmic domain of ca. 340 amino acids, which is much larger than that of EscU (Ghosh, 2004; Moraes et al., 2008). MxiA, its homolog in Shigella, assembles into a homononameric ring that aligns with the secretion channel at the base of the inner membrane machinery (Abrusci et al., 2013). The cytoplasmic domain of several flagellar and virulence EscV homologs has been crystallized, showing that the proteins of the FlhA/YscV family conserve a structural fold of four subdomains, some of which participate in the selfassociation of the monomers that form the nonameric export gate ring (Bange et al., 2010; Lilic et al., 2010; Moore and Jia, 2010; Saijo-Hamano et al., 2010; Worrall et al., 2010). Furthermore, it has been shown that members of this protein family such as FlhA and $\mathrm{HrcV}$ (the EscV homolog in Xanthomonas campestris) interact with different T3S substrates, suggesting that they might play a role in substrate recognition (Bange et al., 2010; Minamino et al., 2012; Hartmann and Buttner, 2013; Kinoshita et al., 2013). In addition, both virulence and flagellar EscV homologs have been implicated in energy conversion from proton-motive force (pmf) into protein export work (Hara et al., 2011; Minamino et al., 2011; Lee et al., 2014). In agreement, it has been proposed that members of the SctV family could actually form a proton channel for energy transduction, coupling proton flow to the T3 secretion process (Minamino et al., 2011; Lee and Rietsch, 2015).
Altogether, considering what has been reported for the homologous proteins, the membrane components of the export apparatus EscRSTUV would contribute to the recruitment and regulation of initial insertion of substrates into the injectisome. Specifically, the C-terminal domains of the flagellar EscV and EscU homologs form a transmembrane export gate that controls substrate access to the T3SS central channel (Minamino and Namba, 2008; Minamino et al., 2010). Regarding the stoichiometry of these membrane components, it was recently demonstrated that the Salmonella SPI-1 export apparatus is composed of $5 \mathrm{SpaP}$ (EscR), 1 SpaQ (EscS), 1 SpaR (EscT), 1 SpaS (EscU), and 9 InvA (EscV) subunits (Zilkenat et al., 2016). The export apparatus components EscRSTU are encoded in the LEE1 operon whose expression is activated immediately after T3SS induction, while the expression of other LEE operons is activated $70 \mathrm{~min}$ after induction (Yerushalmi et al., 2014). In the SPI-1 encoded Salmonella T3SS, the EscRST homologs (SpaPQR) are necessary for the recruitment and assembly of the remaining components of the needle complex (Wagner et al., 2010a). However, in the case of EPEC, interfering with the timing of expression of the LEE1 operon barely affected the T3SS assembly efficiency (Yerushalmi et al., 2014).

\section{Cytoplasmic Components ATPase Complex}

The ATPase complex is formed by the EscN, EscL, and EscO proteins (Figure 2), all of which are important for T3SS function (Deng et al., 2004; Andrade et al., 2007; Ku et al., 2009; Biemans-Oldehinkel et al., 2011; Romo-Castillo et al., 2014). This virulence-associated complex is homologous to the flagellar FliI/FliH/FliJ ATPase complex (Minamino and MacNab, 2000b; Ibuki et al., 2011). The crystal structure of the ATPase EscN has been solved, and like FliI, it shows structural similarity to the F1-ATPase $\alpha$ and $\beta$ subunits (Imada et al., 2007; Zarivach et al., 2007). EscL, like FliH, has been evolutionarily linked to the $b$ and $\delta$ subunits of the F1 ATPase (Pallen et al., 2005, 2006). Even more, despite the lack of sequence conservation, in silico and functional data suggest that EscO is the evolutionary counterpart of the flagellar FliJ protein, which in turn has been related to the $\gamma$ subunit of the F1-ATPase (Ibuki et al., 2011; Romo-Castillo et al., 2014). The functional relatedness of EscO and FliJ was confirmed by heterologous complementation of the motility of a $\Delta f$ liJ mutant with a plasmid encoding EscO (Romo-Castillo et al., 2014). Taken together, these similarities would imply that an energy-producing enzyme, a motility machinery, and an interkingdom protein transport device, share a common evolutionary ancestor.

EscN is a peripheral membrane protein located at the base of the needle complex that energizes the secretion process, probably by releasing the substrate from its cognate chaperone and unfolding it for further secretion, as has been reported for Salmonella InvC, and functioning as a docking site for chaperone-substrate complexes (Gauthier and Finlay, 2003; Akeda and Galán, 2005; Thomas et al., 2005; Chen et al., 2013). This enzyme oligomerizes into a homohexameric ring structure and the oligomeric state of the protein affects its specific activity 
(Andrade et al., 2007; Zarivach et al., 2007). EscN interacts with EscL, a negative regulator that inhibits its ATPase activity, and with EscO, which conversely, stimulates EscN ATPase activity (Biemans-Oldehinkel et al., 2011; Romo-Castillo et al., 2014).

A model proposed for the ATPase complex function that includes previous findings in the flagellar and virulence T3S systems, suggests that the formation of the EscN-EscL complex in the cytoplasm ensures that the ATPase activity is inhibited until ATP hydrolysis can be coupled to protein secretion, preventing futile energy expenditure (Minamino and MacNab, 2000b; Blaylock et al., 2006; Stone et al., 2011). Once the EscN/EscL/EscO complex is formed near the vicinity of the export apparatus through protein-protein interactions with the C-ring, both EscL and EscO, in a similar way to their T3SS counterparts, interact with the major export gate component EscV (Zhu et al., 2002; González-Pedrajo et al., 2006; MoritaIshihara et al., 2006; Hara et al., 2012; Cherradi et al., 2014; Lee et al., 2014), promoting a conformational change that allows EscO to stimulate EscN oligomerization and, subsequently, its ATPase activity (Claret et al., 2003; Evans et al., 2006; Ibuki et al., 2011; Romo-Castillo et al., 2014).

EscO has also been localized in the EPEC periplasm and as previously mentioned, it was found to interact with the OM ring protein EscC (Sal-Man et al., 2012a). In addition, similarly to what has been observed for FliJ, EscO interacts with the chaperones CesA2 (EscG) and CesL (Mpc) (Lin et al., 2014), suggesting that this protein performs additional roles during the T3S process. Likewise, EscL has been recently implicated as a component of the sorting platform as will be discussed next (Lara-Tejero et al., 2011; Hu et al., 2015).

\section{C-ring/Sorting Platform}

In $\mathrm{A} / \mathrm{E}$ pathogens the $\mathrm{C}$-ring is proposed to be a cytoplasmic annular structure located at the base of the basal body, formed mainly by the EscQ protein (formerly known as SepQ), which belongs to the YscQ/FliN (SctQ) protein family (Figure 2; Pallen et al., 2005; Biemans-Oldehinkel et al., 2011). Other members of this family are YscQ (from Yersinia spp.), SpaO (from S. enterica SPI-1), Spa33 (from S. flexneri), SsaQ (from S. enterica SPI-2), and HrcQ (from Xanthomonas spp.) (Morita-Ishihara et al., 2006; Lara-Tejero et al., 2011; Yu et al., 2011; Bzymek et al., 2012; Lorenz et al., 2012; Notti et al., 2015). Three different proteins, FliM, FliN, and FliG, form the corresponding flagellar C-ring, and it has been shown that members of the SctQ family have an evolutionary relationship with FliM and FliN (Zhao et al., 1996; Hueck, 1998; Pallen et al., 2005; Thomas et al., 2006). The mRNA from most of the sctQ homologs contains an internal alternative translation site, giving rise to a full-length protein (SctQ-Full of approximately 300 amino acids) resembling the flagellar FliM protein, and to a shorter C-terminal version (SctQ-C of ca. 100 amino acids) similar to FliN. Both translation products, SctQFull and SctQ-C, are required for T3S assembly and function (Bzymek et al., 2012; Notti et al., 2015; McDowell et al., 2016) with the exception of SsaQ-C from Salmonella SPI-2 that serves as a chaperone for SsaQ-Full but is not essential for T3S (Yu et al., 2011). To date it remains unclear whether EscQ has an internal translation start site.
The SctQ-Full and SctQ-C proteins have been shown to interact in a 1:2 ratio, and it is proposed that this complex assembles into higher order oligomers that form a ring shaped structure (Bzymek et al., 2012; Diepold et al., 2015; McDowell et al., 2016). The SctQ-Full:SctQ-C protein ratio seems to be important for proper injectisome assembly as it was shown that there is a linear correlation between the SctQ-Full structure assembly and the expression levels of SctQ-C protein (Diepold et al., 2015). The injectisome SctQ-Full/SctQ-C complex is believed to mirror the FliM/FliN basic building block of the flagellar C-ring (Bzymek et al., 2012; McDowell et al., 2016). The solved structures of several SctQ proteins revealed the presence of SpoA domains that mediate both SctQ-C-SctQ-C homotypic and SctQ-Full-SctQ-C heterotypic associations (Bzymek et al., 2012; Notti et al., 2015; McDowell et al., 2016). It was recently reported that the $Y$. enterocolitica C-ring is formed by $22 \pm 8$ YscQFull subunits per injectisome and has an estimated diameter of $30.2 \mathrm{~nm}$, making it similar to that of the flagellum (Diepold et al., 2015). Furthermore, $\mathrm{Hu}$ and colleagues determined the structure of the $S$. flexneri C-ring by cryoelectron tomography and showed that it is formed by six pod-like structures made out of multiple copies of Spa33, arranged in a hexagonal array of $32 \mathrm{~nm}$ in diameter and $24 \mathrm{~nm}$ in height. The top portion of the pods, suggested to be composed of Spa33-Full and MxiK, links the entire C-ring to the membrane-associated components of the basal body. The bottom of each pod, proposed to be formed by a homotetramer of Spa33-C, is connected to the ATPase Spa47 (SctN) through six spoke-like densities made out of MxiN (SctL) (Hu et al., 2015). The ultrastructural details of the C-ring in A/E pathogens have not yet been addressed. In Y. enterocolitica it has been shown that the C-ring is a highly dynamic substructure that exchanges subunits between a YscQ cytosolic pool and the assembled structure at the base of the injectisome, and that the rate of this subunit exchange correlates with the effector secretion status (Diepold et al., 2015).

Co-immunoprecipitation experiments in EPEC revealed that EscQ interacts with the ATPase complex components EscN and EscL. Moreover, EscQ was found to be located in the cytoplasm as well as associated with the membrane and this subcellular localization was independent of its binding partners (Biemans-Oldehinkel et al., 2011). Likewise, the EscQ homologs Spa33, YscQ, and SpaO have been shown to interact with members of the SctK and SctL families (MxiK/MxiN, YscK/YscL, OrgA/OrgB; Jackson and Plano, 2000; Jouihri et al., 2003; LaraTejero et al., 2011). In S. enterica, SpaO, OrgA, and OrgB form a large molecular weight complex that interacts with translocators and effectors in a sequential order, leading to the suggestion that the C-ring may act as a sorting platform, queuing the different substrate categories to establish the correct secretion hierarchy. Both chaperones and molecular switch proteins have an active role in this selection process, acting in concert with the sorting platform to ensure an orderly secretion (LaraTejero et al., 2011). In Y. enterocolitica and S. enterica the formation of the C-ring/sorting platform substructure depends on the presence of both SctK (YscK and OrgA) and SctL (YscL and OrgB) proteins (Lara-Tejero et al., 2011; Diepold et al., 2015). In contrast, the sorting platform visualized from Shigella 
$\Delta m x i N$ minicells showed that structural pods are assembled even in absence of the MxiN (SctL) protein (Hu et al., 2015). Based on the information for the homologous proteins, in $\mathrm{A} / \mathrm{E}$ pathogens the sorting platform might be formed by EscQ, EscL, and EscK (formerly Orf4), a component that has been associated with the SctK protein family (Abby and Rocha, 2012; Barison et al., 2013). Like other members of the SctK protein family such as OrgA from Salmonella and MxiK from Shigella, EscK is critical for T3 secretion (Sukhan et al., 2001; Jouihri et al., 2003; Deng et al., 2004). The precise composition and function of the sorting platform in $\mathrm{A} / \mathrm{E}$ pathogens remains to be investigated.

\section{Effectors and Chaperones}

The ultimate goal of T3SS assembly is to modulate host cell functions for the benefit of the bacterium, and this is accomplished by the interplay of the biochemical activities displayed by injected effectors. A/E pathogens share seven effectors encoded in the LEE-PAI, and additionally each pathogen has its own suite of effectors encoded outside the LEE, termed non-LEE-encoded (Nle) effectors, which are encoded on prophages or other integrative elements (McDaniel et al., 1995; Deng et al., 2003, 2004, 2010; Tobe et al., 2006; Iguchi et al., 2009).

The LEE-encoded effectors are Tir, Map, EspF, EspG, EspH, EspZ, and EspB (Garmendia et al., 2005). It has been shown in EPEC that LEE-encoded effectors are hierarchically secreted/translocated into host cells, being Tir the first effector to be injected followed by EspZ, EspF, EspH, EspG, and Map (Thomas et al., 2007; Mills et al., 2008). As previously mentioned, although EspB is a structural translocon component, it is also translocated into host cells but in much lower levels compared to the other effectors, thus precluding a meaningful analysis of its translocation hierarchy (Wolff et al., 1998; Mills et al., 2008). The total number of effectors varies between pathogens, C. rodentium possesses a reported repertoire of at least 29 effectors, while EPEC E2348/69 encodes ca. 22 and EHEC O157:H7 encodes 39 (Tobe et al., 2006; Dean and Kenny, 2009; Petty et al., 2010). Some of the Nle effectors, like NleA/EspI, NleB, NleE, NleF, NleG, $\mathrm{NleH}$, EspJ, and EspL, are common to all LEE-encoding species sequenced to date (Petty et al., 2010). A more recent hierarchical translocation order was reported including both LEE and Nle effectors, in which Tir is again the first one to be injected followed by EspZ, NleA, NleH1, EspF, EspH, NleH2, EspJ, Map, EspG, NleD, NleF, NleB1, NleE1, NleB2, NleC, NleG, NleE2, EspG2, and EspL2 (Mills et al., 2013). For a detailed description of the specific function of effectors in $\mathrm{A} / \mathrm{E}$ pathogens, we refer to reviews on the subject (Dean and Kenny, 2009; Jayamani and Mylonakis, 2014; Santos and Finlay, 2015).

In general, effectors contain one or more C-terminal catalytic domains that manipulate host cell functions, while their $\mathrm{N}$-termini mediates chaperone recognition and transport via the T3SS (Ghosh, 2004). The first ca. 20 amino acids contain the secretion signal sequence necessary and sufficient for T3 secretion (Crawford and Kaper, 2002; Munera et al., 2010; Deng et al., 2015). The chaperone-binding domain is located downstream of the $\mathrm{N}$-terminal secretion signal, usually between amino acids 50 and 100 (Blocker et al., 2003). This domain adopts a linear conformation and wraps around the chaperone dimer through a $\beta$-motif (Lilic et al., 2006).

The T3SS-associated chaperones are small and acidic cytoplasmic proteins important for efficient secretion of their cognate substrates (Feldman and Cornelis, 2003). They promote T3 substrate secretion by contributing to protein stability, aiding in substrate recognition and targeting, preventing premature oligomerization and unspecific interactions, and participating in the establishment of a secretion hierarchy (Wainwright and Kaper, 1998; Abe et al., 1999; Elliott et al., 1999a; Gauthier and Finlay, 2003; Neves et al., 2003; Parsot et al., 2003; Creasey et al., 2003a,c; Thomas et al., 2005, 2007; Su et al., 2008; Chen et al., 2013; Sal-Man et al., 2013; Allison et al., 2014). T3 chaperones function in an ATP-independent manner, although chaperone dissociation from the substrate-chaperone complex is an ATPdependent process (Akeda and Galán, 2005). These proteins have been grouped into three classes depending on their binding substrates: class I chaperones that bind effectors (class IA, one effector and class IB, multiple effectors), class II chaperones that bind translocators, and class III chaperones that bind the needle component (Cornelis and Van Gijsegem, 2000; Page and Parsot, 2002; Parsot et al., 2003; Cornelis, 2006).

The LEE encodes eight proteins that have been characterized as chaperones: CesF, CesL, CesT, CesAB, CesD, CesD2, EscE, and EscG/CesA2 (Wainwright and Kaper, 1998; Elliott et al., 1999a, 2002; Luo et al., 2001; Creasey et al., 2003a,c; Neves et al., 2003; Thomas et al., 2005; Younis et al., 2010; Ramu et al., 2013; Sal-Man et al., 2013). These proteins, with the exception of CesF and CesD2, are critical for $C$. rodentium virulence in mice (Deng et al., 2004). CesT was originally classified as a class IA chaperone for the Tir effector, but subsequent reports showed that it interacts with 10 additional effectors: Map, NleA, NleF, $\mathrm{NleH}, \mathrm{NleH} 2, \mathrm{EspH}, \mathrm{EspZ}, \mathrm{EspF}, \mathrm{NleG}$, and EspG, being reclassified as a multicargo class IB chaperone (Abe et al., 1999; Elliott et al., 1999a; Creasey et al., 2003a,b; Thomas et al., 2005, 2007; Mills et al., 2008). CesF is a class IA chaperone that binds EspF (Elliott et al., 2002) and is required for its translocation (Mills et al., 2008). Additionally, based on sequence similarity searches, CesL was recently classified as a class I chaperone for SepL although it is a special case, since its substrate seems to be an aberrant effector that is not secreted (Younis et al., 2010).

Four class II chaperones have been described in $\mathrm{A} / \mathrm{E}$ pathogens: CesD, CesD2, CesAB, and CesA2. CesD assists EspD and EspB secretion, although it has only been shown to directly interact with EspD (Wainwright and Kaper, 1998), which has an additional chaperone, CesD2 (Neves et al., 2003). The CesAB chaperone differs from the others in that it has a basic pI. It interacts specifically with EspA and EspB, preventing their polymerization, maintaining them partially unfolded and promoting their stabilization (Creasey et al., 2003b; Yip et al., 2005b). Finally, CesA2 was identified in EHEC as a second chaperone for EspA (Su et al., 2008). However, it was later demonstrated in EPEC that CesA2 is a class III chaperone that binds to the needle subunit EscF and therefore, it was named EscG, which together with EscE avoid premature polymerization of the needle (Sal-Man et al., 2013). 


\section{SECRETION REGULATION}

Efficient assembly and function of the T3SS depend on the hierarchical and temporal control of substrate secretion. The assembly of the injectisome is a sequential process that initiates with a Sec-dependent secretion stage in which the OM and IM ring proteins, as well as the export apparatus components, are integrated into the bacterial membranes, then, the ATPase complex and C-ring constituents associate with the basal body to form a functional T3SS (Diepold et al., 2010; Wagner et al., 2010a). Subsequently, the remaining components are secreted in a T3SS-dependent and ordered manner. T3 substrates are classified into three categories according to their temporal secretion: early (inner rod and needle), middle (translocators), and late (effectors) substrates. The hierarchical secretion of these proteins is regulated by two substrate specificity-switching mechanisms that involve protein complexes referred to as molecular switches (Tree et al., 2009; Deane et al., 2010; Büttner, 2012). The secretion regulation mechanisms are reviewed below and a working model for $\mathrm{A} / \mathrm{E}$ pathogens, based on recent studies in the field, is illustrated in Figure 4.

\section{Molecular Switch 1: EscP/EscU}

The transition from early to middle and late substrate secretion occurs once the needle reaches its proper length, a mechanism regulated, as mentioned above, by T3S4 proteins (Minamino et al., 2004; Büttner, 2012), such as EscP from EPEC, YscP from Yersinia, InvJ from Salmonella, Spa32 from Shigella, $\mathrm{HpaC}$ from Xanthomonas and FliK in the flagellar T3SS (Kubori et al., 2000; Magdalena et al., 2002; Tamano et al., 2002; Journet et al., 2003; Minamino et al., 2004; Lorenz et al., 2008; Monjarás Feria et al., 2012). Most T3S4 proteins are secreted, and its absence results in the assembly of abnormally long needle/hook structures (Hirano et al., 1994; Kawagishi et al., 1996; Minamino et al., 1999; Payne and Straley, 1999; Kubori et al., 2000; Stainier et al., 2000; Magdalena et al., 2002; Tamano et al., 2002; Agrain et al., 2005; Waters et al., 2007; Monjarás Feria et al., 2012). Interestingly, $\mathrm{HpaC}$, the only non-secreted T3S4 protein is not involved in pili length regulation (Büttner et al., 2006). The absence of YscP, Spa32, HpaC, and FliK also leads to a reduction or complete absence of middle and/or late substrate secretion, suggesting that besides controlling needle/hook length, T3S4 proteins also promote the secretion substrate specificity switch (Hirano et al., 1994; Kawagishi et al., 1996; Williams et al., 1996; Minamino et al., 1999; Stainier et al., 2000; Magdalena et al., 2002; Tamano et al., 2002; Edqvist et al., 2003; Journet et al., 2003; Botteaux et al., 2008; Morris et al., 2010; Lorenz and Büttner, 2011; Schulz and Büttner, 2011). In EPEC, however, elimination of escP results in a reduced secretion of middle substrates but enhanced secretion of effectors, this led to the proposal that EscP is not indispensable for substrate switching, although it increases the efficiency of the switching event (Monjarás Feria et al., 2012). In agreement, a $\Delta$ spa32 mutant can still form translocation pores and display some RBCs hemolytic activity, indicating that it autonomously switches substrate specificity (Shen et al., 2012).

Substrate switching is regulated by the interaction of T3S4 proteins with members of the SctU export apparatus protein family. T3S4 proteins interact with the C-terminal domain of SctU, as shown for EscP/EscU, Spa32/Spa40, HpaC/HrcU, and FliK/FlhB (Minamino and Macnab, 2000a; Botteaux et al., 2008; Lorenz et al., 2008; Morris et al., 2010; Monjarás Feria et al., 2012). This interaction is proposed to induce conformational changes in SctU proteins that in turn change their specificity of substrate secretion, regulating the switching event. The finding that extragenic suppressor mutations of $f l i K$ and $y s c P$ are localized in the C-terminal domains of $\mathrm{YscU}$ and $\mathrm{FlhB}$, respectively, supports this idea (Kutsukake et al., 1994; Williams et al., 1996; Edqvist et al., 2003).

The YscU/FlhB protein family undergoes spontaneous autocleavage in the NPTH motif found in an exposed region at its $\mathrm{C}$-terminal domain. The two resulting cleavage products remain tightly associated, as has been demonstrated for EscU in EPEC, YscU in Yersinia, Spa40 in Shigella and FlhB in the flagellar T3SS (Minamino and Macnab, 2000a; Deane et al., 2008a; Björnfot et al., 2009; Monjarás Feria et al., 2012). The autoproteolytic event changes the orientation of the PTH loop and is proposed to create a potential interaction surface for other T3SS proteins (Lavander et al., 2002; Ferris et al., 2005; Deane et al., 2008a; Zarivach et al., 2008; Björnfot et al., 2009; Lountos et al., 2009; Wiesand et al., 2009). Since non-cleavable mutants reduce secretion of intermediate and late substrates, it is thought that a docking surface for different T3S substrates might be created upon proteolytic cleavage of SctU proteins (Fraser et al., 2003; Sorg et al., 2007; Zarivach et al., 2008; Lorenz and Büttner, 2011; Thomassin et al., 2011). In EPEC, a subtle conformational change in a conserved surface was observed in non-cleavable mutants (Zarivach et al., 2008). Besides this change in structure, in a noncleavable EscU mutant background, the membrane association of the multicargo chaperone CesT is reduced, suggesting that the cleavage is important for substrate docking; however, no direct interaction between CesT and EscU could be demonstrated (Thomassin et al., 2011). In any case, although indispensable for secretion regulation, the cleavage event per se is not the signal that triggers the substrate secretion change; instead, it might allow YscU/FlhB protein family members to acquire the conformation required for its substrate switching function (Minamino and Macnab, 2000a; Zarivach et al., 2008; Monjarás Feria et al., 2015).

The molecular mechanisms that regulate needle/hook length and the secretion substrate specificity switch have been extensively studied in various systems, leading to the proposal of different models that will be discussed below.

\section{Single Ruler Model}

The observation that the size of YscP correlates with the length of the needle, led Journet and colleagues to propose that this protein functions as a molecular ruler that directly measures needle length (Journet et al., 2003). In this static ruler model, YscP is positioned within the inner channel of the growing needle, with its $\mathrm{N}$ - and $\mathrm{C}$-terminal domains probably contacting the needle tip and the T3SS base, respectively, allowing the secretion of needle subunits. When the molecular ruler is completely stretched, it interacts with YscU at the T3SS base to switch substrate secretion, and gets secreted, finishing the export of needle subunits and permitting middle and late substrate secretion 
A

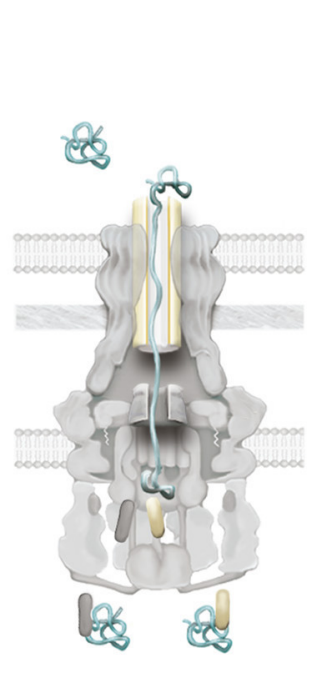

B

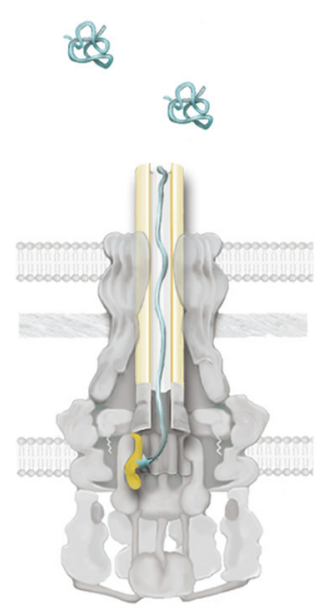

C

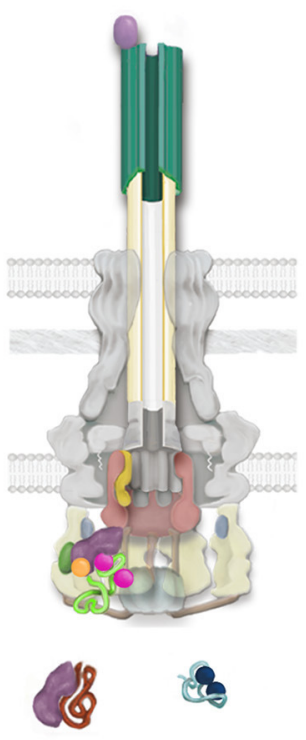

D

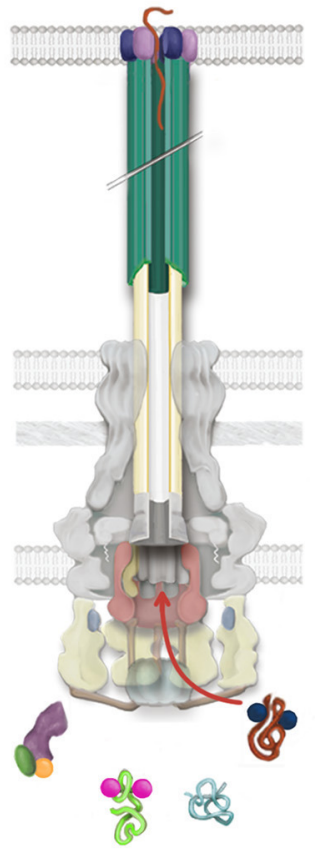

\begin{tabular}{|c|c|c|c|c|c|c|c|c|c|c|}
\hline \&s & 0 & O & 8 & $\beta$ & 0 & ○ & 85 & - & 8 & - \\
\hline EscP & EscI & EscF & EscU & SepL & SepD & CesL & EspA & CesAB & Tir & CesT \\
\hline
\end{tabular}

FIGURE 4 | Model for T3 secretion regulation in A/E pathogens. (A) Rod and needle assembly occur simultaneously (Marlovits et al., 2006; Lefebre and Galán, 2014). EscP directly interacts with early substrates (Escl and EscF, rod and needle subunits, respectively), regulating its secretion. EscP is secreted occasionally during needle assembly. (B) Once rod and needle assembly is completed, EscP makes contact with the full-length needle, causing a pause in substrate secretion that allows the productive interaction between EscP and the pre-cleaved C-terminal domain of EscU (EscUcc) (Monjarás Feria et al., 2012). This interaction is proposed to promote a conformational change in EscUcc that flicks substrate specificity, probably generating a docking site for a different category of substrates (Zarivach et al., 2008; Thomassin et al., 2011). (C) Translocator secretion is now allowed. The SepL/SepD/CesL complex targets translocator/chaperone complexes to the sorting platform (formed by EscQ, EscL, and EscK; Lara-Tejero et al., 2011). SepL also interacts with the export gate component EscV and probably modifies its affinity for certain substrate classes; it has also been proposed that it might block access of effectors to the export gate (Lee et al., 2014; Shen and Blocker, 2016). SepL interacts with the effector Tir, preventing its secretion (Wang et al., 2008). (D) Upon host cell contact, the SepL/SepD/CesL complex might disengage from the export gate component and the sorting platform, alleviating the effector recognition blockade exerted on EscV and allowing effector translocation into host cells.

(Journet et al., 2003). Afterwards it was demonstrated that only one YscP molecule was required for length control and that, while measuring needle length, it preserved its helical structure (Wagner et al., 2009, 2010b). However, since the diameter of an $\alpha$-helix is approximately $10 \AA$ and that of the secretion channel is $13 \AA$, it is impossible to fit a ruler protein and a secreted needle subunit in it (Fujii et al., 2012). Under these same physical constraints, the simultaneous secretion of FliK and hook subunits in the flagellar system was also suggested to be improbable, and therefore an alternative model was proposed for hook length regulation (Shaikh et al., 2005; Moriya et al., 2006).

\section{Infrequent Ruler Model}

In agreement with the previous model, FliK, Spa32, and InvJ have also been demonstrated to act as molecular rulers (Shibata et al., 2007; Botteaux et al., 2008; Erhardt et al., 2011; Wee and Hughes, 2015). However, the proposed needle/hook measurement mechanisms are different. The alternative dynamic-ruler model was originally proposed in the flagellar system by Moriya et al. (2006). This model suggests that during hook assembly FliK is occasionally exported, and that when found in the central channel secretion is briefly paused, allowing the measurement of hook length through the temporary interaction of the $\mathrm{N}$ - and C-terminal domains of FliK with the hook cap FlgD and FlhB, respectively. Short hooks do not allow productive interactions with FliK, inducing its rapid secretion, however, as the hook assembles, more frequent interactions between FliK and the growing structure occur, slowing the secretion rate. Finally, when the hook length reaches approximately $55 \mathrm{~nm}$, the slow secretion rate enables the completely stretched FliK to successfully interact with FlhB, which flips the switch in substrate secretion (Erhardt et al., 2010a, 2011). A similar mechanism was proposed for the needle length control in EPEC. EscP, which directly interacts with EscF, measures needle length upon intermittent secretion during needle assembly (Figure $\mathbf{4 A}$ ). When this structure reaches its final length, all subdomains of EscP can make contact with the needle, promoting a pause in secretion that allows EscP 
to interact with EscU, inducing a conformational change that modifies its specificity from early to middle and late substrates (Figure 4B; Monjarás Feria et al., 2012).

\section{Role of the Inner Rod in Needle Length and Substrate Switching}

An alternative model was proposed for the SPI-1 injectisome in $S$. enterica, which states that the assembly of the inner rod determines the size of the needle. Therefore, the substrate switching is the result of conformational changes produced at the base of the T3SS in response to inner rod assembly completion (Marlovits et al., 2006). Many pieces of evidence support this model. An invJ null mutant, which assembles long needles (Kubori et al., 2000), secretes high levels of the inner rod subunit PrgJ, but fails to assemble this structure, thus, InvJ was proposed to promote inner rod assembly. In addition, the overexpression of PrgJ results in the assembly of shorter needles, apparently because of faster inner rod assembly (Sukhan et al., 2003; Marlovits et al., 2006). Moreover, mutations in PrgJ that slowed the rate of rod assembly, presumably due to impaired subunit-subunit interactions, lead to the assembly of longer needles (Lefebre and Galán, 2014). Likewise, a role of the inner rod component in substrate specificity switching has been proposed in $Y$. pseudotuberculosis. It was shown that the inner rod protein YscI is hypersecreted in a $y s c P$ mutant background and that a suppressor mutation in YscU reestablishes normal YscI secretion, suggesting that the inner rod assembly is important for the substrate specificity switching mechanism (Wood et al., 2008). In EPEC, EscP was shown to directly interact with the inner rod subunit EscI, and it is proposed to regulate its secretion, since an $\operatorname{esc} P$ null mutant hypersecretes EscI (Monjarás Feria et al., 2012). Besides, EscI has also been shown to interact with the export gate protein EscU (Creasey et al., 2003b; Sal-Man et al., 2012b).

It is possible that a combination of these models will contribute to the molecular mechanism of needle length control and substrate specificity switching. Finally, the outcome of the first molecular switch is the assembly of a proper size needle and the trigger of middle and late substrate secretion.

\section{Molecular Switch 2: SepL/SepD}

The second molecular switch regulates differentially the secretion of translocators and effectors. A family of proteins known as gatekeepers participates in this switch. It comprises proteins like SepL from A/E pathogens (Kresse et al., 2000; Deng et al., 2004; O'Connell et al., 2004), MxiC from Shigella (Botteaux et al., 2009), InvE and SsaL from Salmonella SPI-1 and SPI-2, respectively (Kubori and Galán, 2002; Coombes et al., 2004), CopN from Chlamydia (Fields and Hackstadt, 2000), YopN/TyeA from Yersinia (Forsberg et al., 1991; Iriarte et al., 1998), and PopN/Pcr1 from Pseudomonas (Yang et al., 2007). In the latter two cases, the protein is divided in two polypeptide chains that correspond to the $\mathrm{N}$ - and C-terminal domains of the full-length proteins.

In $\mathrm{A} / \mathrm{E}$ pathogens, elimination of SepL abolishes secretion of the translocators and increases secretion of effectors (Deng et al., 2004; O'Connell et al., 2004; Wang et al., 2008). This phenotype is identical to that of the ssaL mutant in the Salmonella SPI-2 (Coombes et al., 2004; Yu et al., 2010). In the case of $\mathrm{MxiC}$ and InvE, their absence results in a decreased secretion of translocators and increased secretion of effectors (Kubori and Galán, 2002; Botteaux et al., 2009; Martinez-Argudo and Blocker, 2010), while elimination of YopN leads to a constitutive secretion of both translocators and effectors (Forsberg et al., 1991; Day and Plano, 1998). These mutant phenotypes suggest that these proteins are bifunctional, promoting translocator secretion (with exception of YopN) and avoiding the premature secretion of effectors (Figure 4C). In EPEC and EHEC SepL interacts with SepD, whose deletion in $\mathrm{A} / \mathrm{E}$ pathogens results in the same phenotype as the sepL null mutant (Deng et al., 2004; O'Connell et al., 2004). Aside from its role in secretion regulation, no further information has been published on SepD function.

\section{Promoting Translocator Secretion}

The mechanism of translocator secretion regulation is not completely understood; however, in Salmonella it was shown that InvE directly interacts with the chaperone/translocator complex, though not with its individual components (Kubori and Galán, 2002). Additionally, the Chlamydial gatekeeper CopN interacts with the translocator-specific chaperone Scc3, and this interaction is important not only for translocator secretion but also for timely secretion prior to effectors (Archuleta and Spiller, 2014). Likewise, Shigella MxiC was shown to interact with the translocator chaperone IpgC (Cherradi et al., 2013). These results highlight the importance of the interaction of the gatekeeper with the translocator/chaperone complex or its individual components in the establishment of the secretion hierarchy. Furthermore, as aforementioned, in a seminal work Lara-Tejero et al. demonstrated the existence of a sorting platform that selects substrates for secretion. Translocators are loaded into the sorting platform in an InvE dependent manner, and elimination of translocators or the gatekeeper results instead in the loading of effectors (Lara-Tejero et al., 2011).

Recently, the crystal structure of SepL from EPEC was determined (Burkinshaw et al., 2015b). It showed that despite the low sequence similarity between gatekeeper proteins, its overall structure is well conserved, with a general architecture consisting of three helical X-bundle domains. When compared to the solved structures of CopN, YopN/TyeA and MxiC (Schubot et al., 2005; Deane et al., 2008b; Archuleta and Spiller, 2014), the SepL structure showed that among the regions conserved between these proteins one corresponds to the binding site of the translocator chaperone $\mathrm{Scc} 3$ in $\mathrm{CopN}$. Protein sequence analysis highlighted the presence of three highly conserved residues: Tyr188, Phe327 and Arg333 (Burkinshaw et al., 2015b). In CopN, Arg365 (equivalent to Arg333 in SepL) is essential for the CopN/Scc3 interaction (Archuleta and Spiller, 2014). In contrast, alanine substitution of Arg333 in SepL did not affect the secretion phenotype (Burkinshaw et al., 2015b), though an interaction between SepL and translocators or their chaperones in $\mathrm{A} / \mathrm{E}$ pathogens has yet to be demonstrated. In conclusion, the precise molecular mechanism through which gatekeepers promote translocator secretion remains an open question. 


\section{Preventing Premature Secretion of Effectors}

The prevention of effector secretion before host cell contact is a common feature of all gatekeeper proteins. For some of them, this regulatory function relies in their ability to be secreted, e.g., YopN, MxiC, CopN, and PopN (Day and Plano, 1998; Fields and Hackstadt, 2000; Yang et al., 2007; Botteaux et al., 2009). In the case of Yersinia, YopN functions like a plug that physically blocks the secretion channel while being attached to the T3SS base through its interaction with TyeA, however, in response to low calcium concentration, this interaction is disrupted, YopN is secreted and the blockade is relieved allowing the secretion of Yops (Cheng et al., 2001). In Chlamydia, the secretion of CopN is also essential for secretion of effectors (Archuleta and Spiller, 2014; Shen et al., 2015). Additionally, a recent model of effector secretion control in Pseudomonas suggests that the PopN complex (PopN, Pcr1, PscB, and Pcr2) is tethered to the T3S apparatus via the Pcr1/PcrD (SepL C-terminal domain/EscV) interaction, blocking the access of effectors to the secretion apparatus. However, when the appropriate signal for effector secretion is received, PopN is secreted, permitting the loading of effectors onto the sorting platform and its subsequent docking to the export gate for secretion (Lee et al., 2014). A similar mechanism was proposed for MxiC from Shigella, in which its interaction with the inner rod protein MxiI, blocks access of effectors to the entry gate. Nevertheless, since this mechanism is also conserved for InvE in Salmonella, which is not secreted, its regulation might rely instead in the ability of MxiC to engage with the rod and not in its secretion capacity (Botteaux et al., 2009; Cherradi et al., 2013).

In $\mathrm{A} / \mathrm{E}$ pathogens, neither SepL nor SepD have been observed to be secreted. Therefore, a different secretion regulation mechanism was proposed in EHEC, in which SepL was shown to bind to the effector Tir. It was demonstrated that while translocators are secreted, the interaction of Tir with SepL delays its secretion, avoiding the premature export of all other effectors, which suggests that this interaction controls the proper timing of secretion (Figure 4C; Wang et al., 2008). This mechanism is supported by the demonstration that Tir secretion is important for the secretion of the rest of the effectors (Thomas et al., 2007). In addition, as aforementioned, there is an established hierarchy in the secretion of effectors in which Tir is the first effector to be secreted (Figure 4D; Mills et al., 2008, 2013). In this regard, it has also been shown that although Tir translocation is not essential for the translocation of other effectors, its absence negatively influences their translocation efficiency (Mills et al., 2013). Finally, it was suggested that different interacting partners of SepL are required for its secretion regulatory function. This is sustained by the fact that the same region of SepL that is required for Tir binding is also essential for its interaction with EscD (Wang et al., 2008).

Even though SepL is not secreted, it was proposed to be an aberrant effector because when fused to a reporter protein, its N-terminal domain is able to mediate protein secretion. Moreover, the SepL-SepD complex was shown to interact with a third protein named CesL, which like SepD, is suggested to function as a SepL chaperone (Younis et al., 2010). The SepL-SepD-CesL complex resembles the YopN/TyeA-YscB-SycN complex in Yersinia (Day and Plano, 1998), PopN/Pcr1-PscBPcr2 complex in Pseudomonas (Yang et al., 2007), CopN-Scc4Scc1complex in Chlamydia (Silva-Herzog et al., 2011) and SsaLSpiC-SsaM complex in Salmonella SPI-2 T3SS (Yu et al., 2010). An outstanding work by $\mathrm{Yu}$ and colleagues demonstrated that the SsaL-SpiC-SsaM complex regulates the secretion hierarchy in response to $\mathrm{pH}$ changes. This protein complex associates with the T3SS base under the acidic conditions of the Salmonellacontaining vacuole, allowing the secretion of translocators while blocking the secretion of effectors. When the translocation pore assembles in the vacuolar membrane, an increase in $\mathrm{pH}$ is detected and transmitted to the T3SS base, which in turn causes dissociation of the SsaL-SpiC-SsaM complex and the degradation of its individual components, permitting the secretion of effectors (Yu et al., 2010). In A/E pathogens it has been shown that, upon removal of calcium from the growth medium, translocator secretion is reduced while effector secretion is increased, a phenotype that partially mimics that of the sepL or sepD mutants (Kenny et al., 1997a; Ide et al., 2003; Deng et al., 2005). This suggests that the absence of calcium might be the environmental cue that regulates the secretion hierarchy, probably through the SepL/SepD complex (Deng et al., 2005).

\section{CONCLUDING REMARKS}

Enteropathogenic and enterohemorrhagic E. coli are an important cause of gastroenteric disease worldwide. These E. coli pathotypes remain as a major public health concern both in the third world population, where EPEC infections predominate, and in developed countries where EHEC is responsible for food-borne outbreaks. The T3SS is an essential virulence trait in the pathogenesis of these bacteria, thus, it is crucial to understand the mechanistic and functional characteristics of this complex machinery. Remarkable advances have been made in the T3SS field in A/E pathogens. To date, almost all of the genes encoded in the LEE PAI have an assigned function, with rorf1 being the exception. Nevertheless, the function of some proteins, such as EscK, has only been deduced based on similarities shared with proteins of other T3S systems. Hence, to have a complete understanding of the injectisome, we must expand our efforts to uncover the precise role of such unexplored components. Moreover, numerous crystal structures of $\mathrm{A} / \mathrm{E}$ pathogens T3SS components have been solved, contributing to a deeper understanding of protein function and interactions, as well as of the overall architecture and assembly of the injectisome. However, there are still several structural and mechanistic details that need to be elucidated, such as determining the precise composition and function of the export apparatus and cytoplasmic components and unraveling the mechanism of protein transport through a $600 \mathrm{~nm}$ filament. In addition, $C$. rodentium has proved to be an invaluable tool for in vivo analyses of T3SS function. Nonetheless, cheaper and more practical invertebrate models such as Galleria mellonella are emerging to understand the virulence mechanisms of $\mathrm{A} / \mathrm{E}$ pathogens (Leuko and Raivio, 2012). T3S regulation has also been studied in $\mathrm{A} / \mathrm{E}$ pathogens, showing that highly conserved mechanisms 
involving two molecular switches and a sorting platform act in coordination to establish a strict hierarchy of substrate secretion. Yet, the physiological signal that triggers effector translocation upon host cell contact is still unknown.

Recent advances in fluorescence microscopy, cryo-electron tomography and single molecule super-resolution techniques have greatly contributed to deciphering the architecture of this complex machine. The use of these tools showed that the T3S systems are not static structures, but instead are dynamic molecular machines that undergo several changes to adapt to different secretion states; for example, employing FRAP (fluorescence recovery after photobleaching), the C-ring main component was demonstrated to exchange between a cytoplasmic and an assembled state (Diepold et al., 2015). In addition, by performing TIRF-FRAP (total internal reflection fluorescence and FRAP) experiments, the ATPase complex was proposed to function as both, a dynamic substrate carrier and a static substrate loader (Bai et al., 2014). Moreover, cryoelectron tomography revealed that these cytoplasmic complexes are structurally stabilized, and the basal body adopts a compacted conformation, upon host cell contact (Nans et al., 2015). Thus, these real time experiments in $\mathrm{A} / \mathrm{E}$ pathogens are required to disclose the dynamic nature of the T3SS in action. Despite all this knowledge, there are multiple open questions that remain elusive, e.g., the signaling cascade from host cell sensing to signal transduction and response of the cytoplasmic components, substrate targeting and docking and the energizing of the secretion process. An intriguing issue is how the T3SS basal machinery recognizes the secretion signal of T3 substrates and which is the precise interaction path that substrate-chaperone complexes have to follow. Likewise, although it has been proposed that the proton motive force is the main energy source for protein transport (Minamino et al., 2011; Lee et al., 2014), the components involved in proton flow coupling to protein secretion are still unknown. The in vitro reconstitution of the T3SS could open up possibilities to solve these problems.

\section{REFERENCES}

Abby, S. S., and Rocha, E. P. (2012). The non-flagellar type III secretion system evolved from the bacterial flagellum and diversified into host-cell adapted systems. PLoS Genet. 8:e1002983. doi: 10.1371/journal.pgen.1002983

Abe, A., de Grado, M., Pfuetzner, R. A., Sánchez-Sanmartín, C., Devinney, R., Puente, J. L., et al. (1999). Enteropathogenic Escherichia coli translocated intimin receptor, Tir, requires a specific chaperone for stable secretion. Mol. Microbiol. 33, 1162-1175.

Abrusci, P., Vergara-Irigaray, M., Johnson, S., Beeby, M. D., Hendrixson, D. R., Roversi, P., et al. (2013). Architecture of the major component of the type III secretion system export apparatus. Nat. Struct. Mol. Biol. 20, 99-104. doi: $10.1038 / \mathrm{nsmb} .2452$

Agrain, C., Sorg, I., Paroz, C., and Cornelis, G. R. (2005). Secretion of YscP from Yersinia enterocolitica is essential to control the length of the injectisome needle but not to change the type III secretion substrate specificity. Mol. Microbiol. 57, 1415-1427. doi: 10.1111/j.1365-2958.2005.04758.x

Akeda, Y., and Galán, J. E. (2005). Chaperone release and unfolding of substrates in type III secretion. Nature 437, 911-915. doi: 10.1038/nature03992

Allen-Vercoe, E., Waddell, B., Livingstone, S., Deans, J., and DeVinney, R. (2006). Enteropathogenic Escherichia coli Tir translocation and pedestal formation requires membrane cholesterol in the absence of bundle-forming pili. Cell. Microbiol. 8, 613-624. doi: 10.1111/j.1462-5822.2005.00654.x
The comprehensive understanding of the structure and function of this complex secretion nanomachine will help to elucidate a way to interfere with this system, preventing bacterial pathogenicity. Drug discovery efforts to inhibit T3SS-mediated virulence in $\mathrm{A} / \mathrm{E}$ pathogens must be guided by new rational approaches such as molecular docking, design of synthetic peptides and high-throughput screenings (Pan et al., 2007; Larzábal et al., 2010; Kimura et al., 2011; Duncan et al., 2012). Recently, the controlled expression of EPEC injectisomes in a non-pathogenic E. coli K-12 strain (Ruano-Gallego et al., 2015), showed the feasibility and the potential of using the T3SS of A/E pathogens as a molecular tool for biotechnological applications and therapeutic purposes. Finally, since poverty, malnutrition and enteric diseases are closely linked, measures to ensure access to clean water sources and basic sanitation services in susceptible communities must be guaranteed.

\section{AUTHOR CONTRIBUTIONS}

All authors listed, have made substantial, direct and intellectual contribution to the work, and approved it for publication.

\section{ACKNOWLEDGMENTS}

We are grateful to Dr Georges Dreyfus and Dr Ignacio CamachoArroyo for critical reading of the manuscript. We thank Mariana Bobadilla Bravo for figure generation and Julia Monjarás Feria for discussions and support. We acknowledge the excellent technical assistance of Norma Espinosa Sánchez. Research in our laboratory related to work discussed in this review was supported by grants from the Dirección General de Asuntos del Personal Académico (DGAPA), UNAM (IN209514), and the Consejo Nacional de Ciencia y Tecnología (CONACyT) (180460) to BG. MG and ES were supported by fellowships from CONACyT (262002 and 349951). VM was supported by a postdoctoral fellowship from DGAPA, UNAM.

Allison, S. E., Tuinema, B. R., Everson, E. S., Sugiman-Marangos, S., Zhang, K., Junop, M. S., et al. (2014). Identification of the docking site between a type III secretion system ATPase and a chaperone for effector cargo. J. Biol. Chem. 289, 23734-23744. doi: 10.1074/jbc.M114.578476

Andrade, A., Pardo, J. P., Espinosa, N., Pérez-Hernández, G., and GonzálezPedrajo, B. (2007). Enzymatic characterization of the enteropathogenic Escherichia coli type III secretion ATPase EscN. Arch. Biochem. Biophys. 468, 121-127. doi: 10.1016/j.abb.2007.09.020

Archuleta, T. L., and Spiller, B. W. (2014). A gatekeeper chaperone complex directs translocator secretion during type three secretion. PLoS Pathog. 10:e1004498. doi: 10.1371/journal.ppat.1004498

Armentrout, E. I., and Rietsch, A. (2016). The Type III secretion translocation pore senses host cell contact. PLoS Pathog. 12:e1005530. doi: 10.1371/journal.ppat.1005530

Armstrong, G. L., Hollingsworth, J., and Morris, J. G. Jr. (1996). Emerging foodborne pathogens: Escherichia coli O157:H7 as a model of entry of a new pathogen into the food supply of the developed world. Epidemiol. Rev. 18, 29-51.

Bai, F., Morimoto, Y. V., Yoshimura, S. D., Hara, N., Kami-Ike, N., Namba, K., et al. (2014). Assembly dynamics and the roles of FliI ATPase of the bacterial flagellar export apparatus. Sci. Rep. 4:6528. doi: 10.1038/srep06528

Bange, G., Kümmerer, N., Engel, C., Bozkurt, G., Wild, K., and Sinning, I. (2010). FlhA provides the adaptor for coordinated delivery of late flagella building 
blocks to the type III secretion system. Proc. Natl. Acad. Sci. U.S.A. 107, 11295-11300. doi: 10.1073/pnas.1001383107

Barba, J., Bustamante, V. H., Flores-Valdez, M. A., Deng, W., Finlay, B. B., and Puente, J. L. (2005). A positive regulatory loop controls expression of the locus of enterocyte effacement-encoded regulators Ler and GrlA. J. Bacteriol. 187, 7918-7930. doi: 10.1128/JB.187.23.7918-7930.2005

Barison, N., Gupta, R., and Kolbe, M. (2013). A sophisticated multi-step secretion mechanism: how the type 3 secretion system is regulated. Cell. Microbiol. 15, 1809-1817. doi: $10.1111 / \mathrm{cmi} .12178$

Barison, N., Lambers, J., Hurwitz, R., and Kolbe, M. (2012). Interaction of MxiG with the cytosolic complex of the type III secretion system controls Shigella virulence. FASEB J. 26, 1717-1726. doi: 10.1096/fj.11-197160

Berdichevsky, T., Friedberg, D., Nadler, C., Rokney, A., Oppenheim, A., and Rosenshine, I. (2005). Ler is a negative autoregulator of the LEE1 operon in enteropathogenic Escherichia coli. J. Bacteriol. 187, 349-357. doi: 10.1128/JB.187.1.349-357.2005

Bergeron, J. R. (2016). Structural modeling of the flagellum MS ring protein FliF reveals similarities to the type III secretion system and sporulation complex. PeerJ 4:e1718. doi: 10.7717/peerj.1718

Bergeron, J. R., Worrall, L. J., Sgourakis, N. G., DiMaio, F., Pfuetzner, R. A., Felise, H. B., et al. (2013). A refined model of the prototypical Salmonella SPI1 T3SS basal body reveals the molecular basis for its assembly. PLoS Pathog. 9:e1003307. doi: 10.1371/journal.ppat.1003307

Bhat, A., Shin, M., Jeong, J. H., Kim, H. J., Lim, H. J., Rhee, J. H., et al. (2014). DNA looping-dependent autorepression of LEE1 P1 promoters by Ler in enteropathogenic Escherichia coli (EPEC). Proc. Natl. Acad. Sci. U.S.A. 111, E2586-E2595. doi: 10.1073/pnas.1322033111

Bieber, D., Ramer, S. W., Wu, C. Y., Murray, W. J., Tobe, T., Fernandez, R., et al. (1998). Type IV pili, transient bacterial aggregates, and virulence of enteropathogenic Escherichia coli. Science 280, 2114-2118.

Biemans-Oldehinkel, E., Sal-Man, N., Deng, W., Foster, L. J., and Finlay, B. B. (2011). Quantitative proteomic analysis reveals formation of an EscL-EscQEscN type III complex in enteropathogenic Escherichia coli. J. Bacteriol. 193, 5514-5519. doi: 10.1128/JB.05235-11

Björnfot, A. C., Lavander, M., Forsberg, A., and Wolf-Watz, H. (2009). Autoproteolysis of $\mathrm{YscU}$ of Yersinia pseudotuberculosis is important for regulation of expression and secretion of Yop proteins. J. Bacteriol. 191, 4259-4267. doi: 10.1128/JB.01730-08

Blaylock, B., Riordan, K. E., Missiakas, D. M., and Schneewind, O. (2006). Characterization of the Yersinia enterocolitica type III secretion ATPase YscN and its regulator, YscL. J. Bacteriol. 188, 3525-3534. doi: 10.1128/JB.188.10.3525-3534.2006

Blocker, A., Jouihri, N., Larquet, E., Gounon, P., Ebel, F., Parsot, C., et al. (2001). Structure and composition of the Shigella flexneri "needle complex", a part of its type III secreton. Mol. Microbiol. 39, 652-663. doi: 10.1046/j.13652958.2001.02200.x

Blocker, A., Komoriya, K., and Aizawa, S. (2003). Type III secretion systems and bacterial flagella: insights into their function from structural similarities. Proc. Natl. Acad. Sci. U.S.A. 100, 3027-3030. doi: 10.1073/pnas.0535 335100

Botteaux, A., Sani, M., Kayath, C. A., Boekema, E. J., and Allaoui, A. (2008). Spa32 interaction with the inner-membrane Spa40 component of the type III secretion system of Shigella flexneri is required for the control of the needle length by a molecular tape measure mechanism. Mol. Microbiol. 70, 1515-1528. doi: 10.1111/j.1365-2958.2008.06499.x

Botteaux, A., Sory, M. P., Biskri, L., Parsot, C., and Allaoui, A. (2009). MxiC is secreted by and controls the substrate specificity of the Shigella flexneri type III secretion apparatus. Mol. Microbiol. 71, 449-460. doi: 10.1111/j.13652958.2008.06537.x

Boyce, T. G., Swerdlow, D. L., and Griffin, P. M. (1995). Escherichia coli O157:H7 and the hemolytic-uremic syndrome. N. Engl. J. Med. 333, 364-368. doi: 10.1056/NEJM199508103330608

Burghout, P., Beckers, F., de Wit, E., van Boxtel, R., Cornelis, G. R., Tommassen, J., et al. (2004). Role of the pilot protein YscW in the biogenesis of the YscC secretin in Yersinia enterocolitica. J. Bacteriol. 186, 5366-5375. doi: 10.1128/JB.186.16.5366-5375.2004

Burkinshaw, B. J., Deng, W., Lameignère, E., Wasney, G. A., Zhu, H., Worrall, L. J., et al. (2015a). Structural analysis of a specialized type III secretion system peptidoglycan-cleaving enzyme. J. Biol. Chem. 290, 10406-10417. doi: 10.1074/jbc.M115.639013

Burkinshaw, B. J., Souza, S. A., and Strynadka, N. C. (2015b). Structural analysis of SepL, an enteropathogenic Escherichia coli type III secretion-system gatekeeper protein. Acta Crystallogr. F. Struct. Biol. Commun. 71(Pt 10), 1300-1308. doi: 10.1107/S2053230X15016064

Burkinshaw, B. J., and Strynadka, N. C. (2014). Assembly and structure of the T3SS. Biochim. Biophys. Acta 1843, 1649-1663. doi: 10.1016/j.bbamcr.2014.01.035

Bustamante, V. H., Santana, F. J., Calva, E., and Puente, J. L. (2001). Transcriptional regulation of type III secretion genes in enteropathogenic Escherichia coli: Ler antagonizes H-NS-dependent repression. Mol. Microbiol. 39, 664-678. doi: 10.1046/j.1365-2958.2001.02209.x

Büttner, D. (2012). Protein export according to schedule: architecture, assembly, and regulation of type III secretion systems from plant- and animal-pathogenic bacteria. Microbiol. Mol. Biol. Rev. 76, 262-310. doi: 10.1128/MMBR.05017-11

Büttner, D., Lorenz, C., Weber, E., and Bonas, U. (2006). Targeting of two effector protein classes to the type III secretion system by a HpaC-and HpaB-dependent protein complex from Xanthomonas campestris pv. vesicatoria. Mol. Microbiol. 59, 513-527. doi: 10.1111/j.1365-2958.2005.04924.x

Bzymek, K. P., Hamaoka, B. Y., and Ghosh, P. (2012). Two translation products of Yersinia yscQ assemble to form a complex essential to type III secretion. Biochemistry 51, 1669-1677. doi: 10.1021/bi201792p

Campellone, K. G., Robbins, D., and Leong, J. M. (2004). EspFU is a translocated EHEC effector that interacts with Tir and N-WASP and promotes Nck-independent actin assembly. Dev. Cell 7, 217-228. doi: 10.1016/j.devcel.2004.07.004

Chatterjee, A., Caballero-Franco, C., Bakker, D., Totten, S., and Jardim, A. (2015). Pore-forming activity of the Escherichia coli Type III secretion system protein EspD. J. Biol. Chem. 290, 25579-25594. doi: 10.1074/jbc.M115.648204

Cheng, L. W., Kay, O., and Schneewind, O. (2001). Regulated secretion of YopN by the type III machinery of Yersinia enterocolitica. J. Bacteriol. 183, 5293-5301. doi: 10.1128/JB.183.18.5293-5301.2001

Chen, L., Ai, X., Portaliou, A. G., Minetti, C. A., Remeta, D. P., Economou, A., et al. (2013). Substrate-activated conformational switch on chaperones encodes a targeting signal in type III secretion. Cell Rep. 3, 709-715. doi: 10.1016/j.celrep.2013.02.025

Cherradi, Y., Hachani, A., and Allaoui, A. (2014). Spa13 of Shigella flexneri has a dual role: chaperone escort and export gate-activator switch of the type III secretion system. Microbiology 160(Pt 1), 130-141. doi: 10.1099/mic.0.071712-0

Cherradi, Y., Schiavolin, L., Moussa, S., Meghraoui, A., Meksem, A., Biskri, L., et al. (2013). Interplay between predicted inner-rod and gatekeeper in controlling substrate specificity of the type III secretion system. Mol. Microbiol. 87, 1183-1199. doi: 10.1111/mmi.12158

Claret, L., Calder, S. R., Higgins, M., and Hughes, C. (2003). Oligomerization and activation of the FliI ATPase central to bacterial flagellum assembly. Mol. Microbiol. 48, 1349-1355. doi: 10.1046/j.1365-2958.2003.03506.x

Cleary, J., Lai, L. C., Shaw, R. K., Straatman-Iwanowska, A., Donnenberg, M. S., Frankel, G., et al. (2004). Enteropathogenic Escherichia coli (EPEC) adhesion to intestinal epithelial cells: role of bundle-forming pili (BFP), EspA filaments and intimin. Microbiology 150(Pt 3), 527-538. doi: 10.1099/mic.0.26740-0

Collins, J. W., Keeney, K. M., Crepin, V. F., Rathinam, V. A., Fitzgerald, K. A., Finlay, B. B., et al. (2014). Citrobacter rodentium: infection, inflammation and the microbiota. Nat. Rev. Microbiol. 12, 612-623. doi: 10.1038/nrmic ro3315

Connolly, J. P., Finlay, B. B., and Roe, A. J. (2015). From ingestion to colonization: the influence of the host environment on regulation of the LEE encoded type III secretion system in enterohaemorrhagic Escherichia coli. Front. Microbiol. 6:568. doi: $10.3389 /$ fmicb.2015.00568

Coombes, B. K., Brown, N. F., Valdez, Y., Brumell, J. H., and Finlay, B. B. (2004). Expression and secretion of Salmonella pathogenicity island-2 virulence genes in response to acidification exhibit differential requirements of a functional type III secretion apparatus and SsaL. J. Biol. Chem. 279, 49804-49815. doi: 10.1074/jbc.M404299200

Cornelis, G. R. (2006). The type III secretion injectisome. Nat. Rev. Microbiol. 4, 811-825. doi: 10.1038/nrmicro1526

Cornelis, G. R., and Van Gijsegem, F. (2000). Assembly and function of type III secretory systems. Annu. Rev. Microbiol. 54, 735-774. doi: 10.1146/annurev.micro.54.1.735 
Crago, A. M., and Koronakis, V. (1998). Salmonella InvG forms a ring-like multimer that requires the InvH lipoprotein for outer membrane localization. Mol. Microbiol. 30, 47-56.

Crawford, J. A., and Kaper, J. B. (2002). The N-terminus of enteropathogenic Escherichia coli (EPEC) Tir mediates transport across bacterial and eukaryotic cell membranes. Mol. Microbiol. 46, 855-868. doi: 10.1046/j.1365-2958.2002.03214.x

Creasey, E. A., Delahay, R. M., Bishop, A. A., Shaw, R. K., Kenny, B., Knutton, S., et al. (2003a). CesT is a bivalent enteropathogenic Escherichia coli chaperone required for translocation of both Tir and Map. Mol. Microbiol. 47, 209-221. doi: 10.1046/j.1365-2958.2003.03290.x

Creasey, E. A., Delahay, R. M., Daniell, S. J., and Frankel, G. (2003b). Yeast two-hybrid system survey of interactions between LEE-encoded proteins of enteropathogenic Escherichia coli. Microbiology 149(Pt 8), 2093-2106. doi: 10.1099/mic.0.26355-0

Creasey, E. A., Friedberg, D., Shaw, R. K., Umanski, T., Knutton, S., Rosenshine, I., et al. (2003c). CesAB is an enteropathogenic Escherichia coli chaperone for the type-III translocator proteins EspA and EspB. Microbiology 149(Pt 12), 3639-3647. doi: 10.1099/mic.0.26735-0

Crepin, V. F., Prasannan, S., Shaw, R. K., Wilson, R. K., Creasey, E., Abe, C. M., et al. (2005a). Structural and functional studies of the enteropathogenic Escherichia coli type III needle complex protein EscJ. Mol. Microbiol. 55, 1658-1670. doi: 10.1111/j.1365-2958.2005.04508.x

Crepin, V. F., Shaw, R., Abe, C. M., Knutton, S., and Frankel, G. (2005b). Polarity of enteropathogenic Escherichia coli EspA filament assembly and protein secretion. J. Bacteriol. 187, 2881-2889. doi: 10.1128/JB.187.8.2881-2889.2005

Dahan, S., Knutton, S., Shaw, R. K., Crepin, V. F., Dougan, G., and Frankel, G. (2004). Transcriptome of enterohemorrhagic Escherichia coli O157 adhering to eukaryotic plasma membranes. Infect. Immun. 72, 5452-5459. doi: 10.1128/IAI.72.9.5452-5459.2004

Daniell, S. J., Delahay, R. M., Shaw, R. K., Hartland, E. L., Pallen, M. J., Booy, F., et al. (2001a). Coiled-coil domain of enteropathogenic Escherichia coli type III secreted protein EspD is involved in EspA filament-mediated cell attachment and hemolysis. Infect. Immun. 69, 4055-4064. doi: 10.1128/IAI.69.6.40554064.2001

Daniell, S. J., Kocsis, E., Morris, E., Knutton, S., Booy, F. P., and Frankel, G. (2003). 3D structure of EspA filaments from enteropathogenic Escherichia coli. Mol. Microbiol. 49, 301-308. doi: 10.1046/j.1365-2958.2003.03555.x

Daniell, S. J., Takahashi, N., Wilson, R., Friedberg, D., Rosenshine, I., Booy, F. P., et al. (2001b). The filamentous type III secretion translocon of enteropathogenic Escherichia coli. Cell. Microbiol. 3, 865-871. doi: 10.1046/j.1462-5822.2001.00168.x

Dasanayake, D., Richaud, M., Cyr, N., Caballero-Franco, C., Pittroff, S., Finn, R. M., et al. (2011). The N-terminal amphipathic region of the Escherichia coli type III secretion system protein EspD is required for membrane insertion and function. Mol. Microbiol. 81, 734-750. doi: 10.1111/j.1365-2958.2011.07727.x

Day, J. B., and Plano, G. V. (1998). A complex composed of SycN and YscB functions as a specific chaperone for YopN in Yersinia pestis. Mol. Microbiol. 30, 777-788.

Deane, J. E., Abrusci, P., Johnson, S., and Lea, S. M. (2010). Timing is everything: the regulation of type III secretion. Cell. Mol. Life Sci. 67, 1065-1075. doi: 10.1007/s00018-009-0230-0

Deane, J. E., Graham, S. C., Mitchell, E. P., Flot, D., Johnson, S., and Lea, S. M. (2008a). Crystal structure of Spa40, the specificity switch for the Shigella flexneri type III secretion system. Mol. Microbiol. 69, 267-276. doi: 10.1111/j.13652958.2008.06293.x

Deane, J. E., Roversi, P., King, C., Johnson, S., and Lea, S. M. (2008b). Structures of the Shigella flexneri type 3 secretion system protein MxiC reveal conformational variability amongst homologues. J. Mol. Biol. 377, 985-992. doi: 10.1016/j.jmb.2008.01.072

Dean, P., and Kenny, B. (2009). The effector repertoire of enteropathogenic E. coli: ganging up on the host cell. Curr. Opin. Microbiol. 12, 101-109. doi: 10.1016/j.mib.2008.11.006

Delahay, R. M., and Frankel, G. (2002). Coiled-coil proteins associated with type III secretion systems: a versatile domain revisited. Mol. Microbiol. 45, 905-916. doi: 10.1046/j.1365-2958.2002.03083.x

Delahay, R. M., Knutton, S., Shaw, R. K., Hartland, E. L., Pallen, M. J., and Frankel, G. (1999). The coiled-coil domain of EspA is essential for the assembly of the type III secretion translocon on the surface of enteropathogenic Escherichia coli. J. Biol. Chem. 274, 35969-35974.

Deng, W., de Hoog, C. L., Yu, H. B., Li, Y., Croxen, M. A., Thomas, N. A., et al. (2010). A comprehensive proteomic analysis of the type III secretome of Citrobacter rodentium. J. Biol. Chem. 285, 6790-6800. doi: 10.1074/jbc.M109.086603

Deng, W., Li, Y., Hardwidge, P. R., Frey, E. A., Pfuetzner, R. A., Lee, S., et al. (2005). Regulation of type III secretion hierarchy of translocators and effectors in attaching and effacing bacterial pathogens. Infect. Immun. 73, 2135-2146. doi: 10.1128/IAI.73.4.2135-2146.2005

Deng, W., Li, Y., Vallance, B. A., and Finlay, B. B. (2001). Locus of enterocyte effacement from Citrobacter rodentium: Sequence analysis and evidence for horizontal transfer among attaching and effacing pathogens. Infect. Immun. 69, 6323-6335. doi: 10.1128/IAI.69.10.6323-6335.2001

Deng, W., Puente, J. L., Gruenheid, S., Li, Y., Vallance, B. A., Vázquez, A., et al. (2004). Dissecting virulence: systematic and functional analyses of a pathogenicity island. Proc. Natl. Acad. Sci. U.S.A. 101, 3597-3602. doi: 10.1073/pnas.0400326101

Deng, W., Vallance, B. A., Li, Y., Puente, J. L., and Finlay, B. B. (2003). Citrobacter rodentium translocated intimin receptor (Tir) is an essential virulence factor needed for actin condensation, intestinal colonization and colonic hyperplasia in mice. Mol. Microbiol. 48, 95-115. doi: 10.1046/j.1365-2958.2003.03429.x

Deng, W., Yu, H. B., de Hoog, C. L., Stoynov, N., Li, Y., Foster, L. J., et al. (2012). Quantitative proteomic analysis of type III secretome of enteropathogenic Escherichia coli reveals an expanded effector repertoire for attaching/effacing bacterial pathogens. Mol. Cell. Prot. 11, 692-709. doi: 10.1074/mcp.M111.013672

Deng, W., Yu, H. B., Li, Y., and Finlay, B. B. (2015). SepD/SepL-dependent secretion signals of the type III secretion system translocator proteins in enteropathogenic Escherichia coli. J. Bacteriol. 197, 1263-1275. doi: 10.1128/JB.02401-14

Diepold, A., Amstutz, M., Abel, S., Sorg, I., Jenal, U., and Cornelis, G. R. (2010). Deciphering the assembly of the Yersinia type III secretion injectisome. EMBO J. 29, 1928-1940. doi: 10.1038/emboj.2010.84

Diepold, A., Kudryashev, M., Delalez, N. J., Berry, R. M., and Armitage, J. P. (2015). Composition, formation, and regulation of the cytosolic c-ring, a dynamic component of the type III secretion injectisome. PLoS Biol. 13:e1002039. doi: 10.1371/journal.pbio.1002039

Diepold, A., and Wagner, S. (2014). Assembly of the bacterial type III secretion machinery. FEMS Microbiol. Rev. 38, 802-822. doi: 10.1111/1574-6976. 12061

Discola, K. F., Förster, A., Boulay, F., Simorre, J. P., Attree, I., Dessen, A., et al. (2014). Membrane and chaperone recognition by the major translocator protein PopB of the type III secretion system of Pseudomonas aeruginosa. J. Biol. Chem. 289, 3591-3601. doi: 10.1074/jbc.M113.517920

Dohlich, K., Zumsteg, A. B., Goosmann, C., and Kolbe, M. (2014). A substratefusion protein is trapped inside the Type III Secretion System channel in Shigella flexneri. PLoS Pathog. 10:e1003881. doi: 10.1371/journal.ppat.1003881

Donnenberg, M. S., and Kaper, J. B. (1991). Construction of an eae deletion mutant of enteropathogenic Escherichia coli by using a positive-selection suicide vector. Infect. Immun. 59, 4310-4317.

Donnenberg, M. S., and Kaper, J. B. (1992). Enteropathogenic Escherichia coli. Infect. Immun. 60, 3953-3961.

Donnenberg, M. S., Tacket, C. O., James, S. P., Losonsky, G., Nataro, J. P., Wasserman, S. S., et al. (1993). Role of the eaeA gene in experimental enteropathogenic Escherichia coli infection. J. Clin. Invest. 92, 1412-1417. doi: 10.1172/JCI116717

Dorman, C. J. (2004). H-NS: a universal regulator for a dynamic genome. Nat. Rev. Microbiol. 2, 391-400. doi: 10.1038/nrmicro883

Duncan, M. C., Linington, R. G., and Auerbuch, V. (2012). Chemical inhibitors of the type three secretion system: disarming bacterial pathogens. Antimicrob. Agents Chemother. 56, 5433-5441. doi: 10.1128/AAC.00975-12

Ebel, F., Podzadel, T., Rohde, M., Kresse, A. U., Krämer, S., Deibel, C., et al (1998). Initial binding of Shiga toxin-producing Escherichia coli to host cells and subsequent induction of actin rearrangements depend on filamentous EspA-containing surface appendages. Mol. Microbiol. 30, 147-161.

Edqvist, P. J., Olsson, J., Lavander, M., Sundberg, L., Forsberg, A., Wolf-Watz, H., et al. (2003). YscP and YscU regulate substrate specificity of the Yersinia type 
III secretion system. J. Bacteriol. 185, 2259-2266. doi: 10.1128/JB.185.7.22592266.2003

Elliott, S. J., Hutcheson, S. W., Dubois, M. S., Mellies, J. L., Wainwright, L. A., Batchelor, M., et al. (1999a). Identification of CesT, a chaperone for the type III secretion of Tir in enteropathogenic Escherichia coli. Mol. Microbiol. 33, 1176-1189.

Elliott, S. J., O’Connell, C. B., Koutsouris, A., Brinkley, C., Donnenberg, M. S., Hecht, G., et al. (2002). A gene from the locus of enterocyte effacement that is required for enteropathogenic Escherichia coli to increase tight-junction permeability encodes a chaperone for EspF. Infect. Immun. 70, 2271-2277. doi: 10.1128/IAI.70.5.2271-2277.2002

Elliott, S. J., Wainwright, L. A., McDaniel, T. K., Jarvis, K. G., Deng, Y. K., Lai, L. C., et al. (1998). The complete sequence of the locus of enterocyte effacement (LEE) from enteropathogenic Escherichia coli E2348/69. Mol. Microbiol. 28, 1-4.

Elliott, S. J., Yu, J., and Kaper, J. B. (1999b). The cloned locus of enterocyte effacement from enterohemorrhagic Escherichia coli O157:H7 is unable to confer the attaching and effacing phenotype upon E. coli K-12. Infect. Immun. $67,4260-4263$.

Erhardt, M., Hirano, T., Su, Y., Paul, K., Wee, D. H., Mizuno, S., et al. (2010a). The role of the FliK molecular ruler in hook-length control in Salmonella enterica. Mol. Microbiol. 75, 1272-1284. doi: 10.1111/j.1365-2958.2010.07050.x

Erhardt, M., Namba, K., and Hughes, K. T. (2010b). Bacterial Nanomachines: The flagellum and type III injectisome. Cold Spring Harb. Perspect. Biol. 2:a000299. doi: $10.1101 /$ cshperspect.a000299

Erhardt, M., Singer, H. M., Wee, D. H., Keener, J. P., and Hughes, K. T. (2011). An infrequent molecular ruler controls flagellar hook length in Salmonella enterica. EMBO J. 30, 2948-2961. doi: 10.1038/emboj.2011.185

Evans, L. D., Stafford, G. P., Ahmed, S., Fraser, G. M., and Hughes, C. (2006). An escort mechanism for cycling of export chaperones during flagellum assembly. Proc. Natl. Acad. Sci. U.S.A. 103, 17474-17479. doi: 10.1073/pnas.0605197103

Feldman, M. F., and Cornelis, G. R. (2003). The multitalented type III chaperones: all you can do with $15 \mathrm{kDa}$. FEMS Microbiol. Lett. 219, 151-158. doi: 10.1016/S0378-1097(03)00042-9

Feldman, M. F., Müller, S., Wüest, E., and Cornelis, G. R. (2002). SycE allows secretion of YopE-DHFR hybrids by the Yersinia enterocolitica type III Ysc system. Mol. Microbiol. 46, 1183-1197. doi: 10.1046/j.1365-2958.2002.03241.x

Ferris, H. U., Furukawa, Y., Minamino, T., Kroetz, M. B., Kihara, M., Namba, K., et al. (2005). FlhB regulates ordered export of flagellar components via autocleavage mechanism. J. Biol. Chem. 280, 41236-41242. doi: 10.1074/jbc.M509438200

Fields, K. A., and Hackstadt, T. (2000). Evidence for the secretion of Chlamydia trachomatis CopN by a type III secretion mechanism. Mol. Microbiol. 38, 1048-1060. doi: 10.1046/j.1365-2958.2000.02212.x

Fitzhenry, R. J., Pickard, D. J., Hartland, E. L., Reece, S., Dougan, G., Phillips, A. D., et al. (2002). Intimin type influences the site of human intestinal mucosal colonisation by enterohaemorrhagic Escherichia coli O157:H7. Gut 50, 180-185. doi: 10.1136/gut.50.2.180

Forsberg, A., Viitanen, A. M., Skurnik, M., and Wolf-Watz, H. (1991). The surfacelocated YopN protein is involved in calcium signal transduction in Yersinia pseudotuberculosis. Mol. Microbiol. 5, 977-986.

Frankel, G., Phillips, A. D., Rosenshine, I., Dougan, G., Kaper, J. B., and Knutton, S. (1998). Enteropathogenic and enterohaemorrhagic Escherichia coli: more subversive elements. Mol. Microbiol. 30, 911-921.

Franzin, F. M., and Sircili, M. P. (2015). Locus of enterocyte effacement: a pathogenicity island involved in the virulence of enteropathogenic and enterohemorragic Escherichia coli subjected to a complex network of gene regulation. Biomed Res. Int. 2015:534738. doi: 10.1155/2015/ 534738

Fraser, G. M., Hirano, T., Ferris, H. U., Devgan, L. L., Kihara, M., and Macnab, R. M. (2003). Substrate specificity of type III flagellar protein export in Salmonella is controlled by subdomain interactions in FlhB. Mol. Microbiol. 48, 1043-1057. doi: 10.1046/j.1365-2958.2003.03487.x

Fujii, T., Cheung, M., Blanco, A., Kato, T., Blocker, A. J., and Namba, K. (2012). Structure of a type III secretion needle at 7-A resolution provides insights into its assembly and signaling mechanisms. Proc. Natl. Acad. Sci. U.S.A. 109, 4461-4466. doi: 10.1073/pnas.1116126109

Gamez, A., Mukerjea, R., Alayyoubi, M., Ghassemian, M., and Ghosh, P. (2012). Structure and interactions of the cytoplasmic domain of the Yersinia type
III secretion protein YscD. J. Bacteriol. 194, 5949-5958. doi: 10.1128/JB.00 513-12

García-Gómez, E., Espinosa, N., de la Mora, J., Dreyfus, G., and Gonźlez-Pedrajo, B. (2011). The muramidase EtgA from enteropathogenic Escherichia coli is required for efficient type III secretion. Microbiology 157(Pt 4), 1145-1160. doi: 10.1099/mic.0.045617-0

Garmendia, J., Frankel, G., and Crepin, V. F. (2005). Enteropathogenic and enterohemorrhagic Escherichia coli infections: translocation, translocation, translocation. Infect. Immun. 73, 2573-2585. doi: 10.1128/IAI.73.5.25732585.2005

Gauthier, A., and Finlay, B. B. (2003). Translocated intimin receptor and its chaperone interact with ATPase of the type III secretion apparatus of enteropathogenic Escherichia coli. J. Bacteriol. 185, 6747-6755. doi: 10.1128/JB.185.23.6747-6755.2003

Gauthier, A., Puente, J. L., and Finlay, B. B. (2003). Secretin of the enteropathogenic Escherichia coli type III secretion system requires components of the type III apparatus for assembly and localization. Infect. Immun. 71, 3310-3319. doi: 10.1128/IAI.71.6.3310-3319.2003

Genin, S., and Boucher, C. A. (1994). A superfamily of proteins involved in different secretion pathways in gram-negative bacteria: modular structure and specificity of the N-terminal domain. Mol. Gen. Genet. 243, 112-118.

Ghosh, P. (2004). Process of protein transport by the type III secretion system. Microbiol. Mol. Biol. Rev. 68, 771-795. doi: 10.1128/MMBR.68.4.771-795.2004

Girón, J. A., Ho, A. S., and Schoolnik, G. K. (1991). An inducible bundle-forming pilus of enteropathogenic Escherichia coli. Science 254, 710-713.

Girón, J. A., Torres, A. G., Freer, E., and Kaper, J. B. (2002). The flagella of enteropathogenic Escherichia coli mediate adherence to epithelial cells. Mol. Microbiol. 44, 361-379. doi: 10.1046/j.1365-2958.2002.02899.x

Gómez-Duarte, O. G., and Kaper, J. B. (1995). A plasmid-encoded regulatory region activates chromosomal eaeA expression in enteropathogenic Escherichia coli. Infect. Immun. 63, 1767-1776.

González-Pedrajo, B., Minamino, T., Kihara, M., and Namba, K. (2006). Interactions between $\mathrm{C}$ ring proteins and export apparatus components: a possible mechanism for facilitating type III protein export. Mol. Microbiol. 60, 984-998. doi: 10.1111/j.1365-2958.2006.05149.x

Goosney, D. L., Gruenheid, S., and Finlay, B. B. (2000). Gut feelings: enteropathogenic E. coli (EPEC) interactions with the host. Ann. Rev. Cell Develop. Biol. 16, 173-189. doi: 10.1146/annurev.cellbio.16.1.173

Guignot, J., Segura, A., and Tran Van Nhieu, G. (2015). The serine protease EspC from Enteropathogenic Escherichia coli regulates pore formation and cytotoxicity mediated by the Type III secretion system. PLoS Pathog. 11:e1005013. doi: 10.1371/journal.ppat.1005013

Hara, N., Morimoto, Y. V., Kawamoto, A., Namba, K., and Minamino, T. (2012). Interaction of the extreme $\mathrm{N}$-terminal region of FliH with FlhA is required for efficient bacterial flagellar protein export. J. Bacteriol. 194, 5353-5360. doi: 10.1128/JB.01028-12

Hara, N., Namba, K., and Minamino, T. (2011). Genetic characterization of conserved charged residues in the bacterial flagellar type III export protein FlhA. PLoS ONE 6:e22417. doi: 10.1371/journal.pone.0022417

Hardwidge, P. R., Deng, W., Vallance, B. A., Rodriguez-Escudero, I., Cid, V. J., Molina, M., et al. (2005). Modulation of host cytoskeleton function by the enteropathogenic Escherichia coli and Citrobacter rodentium effector protein EspG. Infect. Immun. 73, 2586-2594. doi: 10.1128/IAI.73.5.2586-2594.2005

Hartland, E. L., Daniell, S. J., Delahay, R. M., Neves, B. C., Wallis, T., Shaw, R. K., et al. (2000). The type III protein translocation system of enteropathogenic Escherichia coli involves EspA-EspB protein interactions. Mol. Microbiol. 35, 1483-1492. doi: 10.1046/j.1365-2958.2000.01814.x

Hartmann, N., and Buttner, D. (2013). The inner membrane protein HrcV from Xanthomonas spp. is involved in substrate docking during type III secretion. Mol. Plant Microbe Interact. 26, 1176-1189. doi: 10.1094/MPMI-01-1 3-0019-R

Hayward, R. D., Cain, R. J., McGhie, E. J., Phillips, N., Garner, M. J., and Koronakis, V. (2005). Cholesterol binding by the bacterial type III translocon is essential for virulence effector delivery into mammalian cells. Mol. Microbiol. 56, 590-603. doi: 10.1111/j.1365-2958.2005.04568.x

Hirano, T., Yamaguchi, S., Oosawa, K., and Aizawa, S. (1994). Roles of FliK and FlhB in determination of flagellar hook length in Salmonella typhimurium. J. Bacteriol. 176, 5439-5449. 
Hodges, K., Alto, N. M., Ramaswamy, K., Dudeja, P. K., and Hecht, G. (2008). The enteropathogenic Escherichia coli effector protein EspF decreases sodium hydrogen exchanger 3 activity. Cell. Microbiol. 10, 1735-1745. doi: 10.1111/j.1462-5822.2008.01163.x

Hodgkinson, J. L., Horsley, A., Stabat, D., Simon, M., Johnson, S., da Fonseca, P. C., et al. (2009). Three-dimensional reconstruction of the Shigella T3SS transmembrane regions reveals 12 -fold symmetry and novel features throughout. Nat. Struct. Mol. Biol. 16, 477-485. doi: 10.1038/nsmb.1599

Hoiczyk, E., and Blobel, G. (2001). Polymerization of a single protein of the pathogen Yersinia enterocolitica into needles punctures eukaryotic cells. Proc. Natl. Acad. Sci. U.S.A. 98, 4669-4674. doi: 10.1073/pnas.071065798

Huang, L. H., and Syu, W. J. (2008). GrlA of enterohemorrhagic Escherichia coli O157:H7 activates LEE1 by binding to the promoter region. J. Microbiol. Immunol. Infect. 41, 9-16.

Hu, B., Morado, D. R., Margolin, W., Rohde, J. R., Arizmendi, O., Picking, W. L., et al. (2015). Visualization of the type III secretion sorting platform of Shigella flexneri. Proc. Natl. Acad. Sci. U.S.A. 112, 1047-1052. doi: $10.1073 /$ pnas. 1411610112

Hueck, C. J. (1998). Type III protein secretion systems in bacterial pathogens of animals and plants. Microbiol. Mol. Biol. Rev. 62, 379-433.

Ibuki, T., Imada, K., Minamino, T., Kato, T., Miyata, T., and Namba, K. (2011). Common architecture of the flagellar type III protein export apparatus and F- and V-type ATPases. Nat. Struct. Mol. Biol. 18, 277-282. doi: 10.1038/nsmb.1977

Ide, T., Laarmann, S., Greune, L., Schillers, H., Oberleithner, H., and Schmidt, M. A. (2001). Characterization of translocation pores inserted into plasma membranes by type III-secreted Esp proteins of enteropathogenic Escherichia coli. Cell. Microbiol. 3, 669-679. doi: 10.1046/j.1462-5822.2001. 00146.x

Ide, T., Michgehl, S., Knappstein, S., Heusipp, G., and Schmidt, M. A. (2003). Differential modulation by Ca2+ of type III secretion of diffusely adhering enteropathogenic Escherichia coli. Infect. Immun. 71, 1725-1732. doi: 10.1128/IAI.71.4.1725-1732.2003

Iguchi, A., Thomson, N. R., Ogura, Y., Saunders, D., Ooka, T., Henderson, I. R., et al. (2009). Complete genome sequence and comparative genome analysis of enteropathogenic Escherichia coli O127:H6 strain E2348/69. J. Bacteriol. 191, 347-354. doi: 10.1128/JB.01238-08

Iizumi, Y., Sagara, H., Kabe, Y., Azuma, M., Kume, K., Ogawa, M., et al. (2007). The enteropathogenic E. coli effector EspB facilitates microvillus effacing and antiphagocytosis by inhibiting myosin function. Cell Host Microbe. 2, 383-392. doi: 10.1016/j.chom.2007.09.012

Imada, K., Minamino, T., Tahara, A., and Namba, K. (2007). Structural similarity between the flagellar type III ATPase Flil and F-1-ATPase subunits. Proc. Natl. Acad. Sci. U.S.A. 104, 485-490. doi: 10.1073/pnas.0608090104

Iriarte, M., Sory, M. P., Boland, A., Boyd, A. P., Mills, S. D., Lambermont, I., et al. (1998). TyeA, a protein involved in control of Yop release and in translocation of Yersinia Yop effectors. EMBO J. 17, 1907-1918. doi: 10.1093/emboj/17.7.1907

Iyoda, S., and Watanabe, H. (2004). Positive effects of multiple pch genes on expression of the locus of enterocyte effacement genes and adherence of enterohaemorrhagic Escherichia coli O157: H7 to HEp-2 cells. Microbiology 150(Pt 7), 2357-2571. doi: 10.1099/mic.0.27100-0

Jackson, M. W., and Plano, G. V. (2000). Interactions between type III secretion apparatus components from Yersinia pestis detected using the yeast two-hybrid system. FEMS Microbiol. Lett. 186, 85-90. doi: 10.1111/j.15746968.2000.tb09086.x

Jarvis, K. G., Girón, J. A., Jerse, A. E., McDaniel, T. K., Donnenberg, M. S., and Kaper, J. B. (1995). Enteropathogenic Escherichia coli contains a putative type III secretion system necessary for the export of proteins involved in attaching and effacing lesion formation. Proc. Natl. Acad. Sci. U.S.A. 92, 7996-8000.

Jayamani, E., and Mylonakis, E. (2014). Effector triggered manipulation of host immune response elicited by different pathotypes of Escherichia coli. Virulence 5, 733-739. doi: 10.4161/viru.29948

Jerse, A. E., and Kaper, J. B. (1991). The eae gene of enteropathogenic Escherichia coli encodes a 94-kilodalton membrane protein, the expression of which is influenced by the EAF plasmid. Infect. Immun. 59, 4302-4309.

Jiménez, R., Cruz-Migoni, S. B., Huerta-Saquero, A., Bustamante, V. H., and Puente, J. L. (2010). Molecular characterization of GrlA, a specific positive regulator of ler expression in enteropathogenic Escherichia coli. J. Bacteriol. 192, 4627-4642. doi: 10.1128/JB.00307-10

Jouihri, N., Sory, M. P., Page, A. L., Gounon, P., Parsot, C., and Allaoui, A. (2003). MxiK and MxiN interact with the Spa47 ATPase and are required for transit of the needle components $\mathrm{MxiH}$ and MxiI, but not of Ipa proteins, through the type III secretion apparatus of Shigella flexneri. Mol. Microbiol. 49, 755-767. doi: 10.1046/j.1365-2958.2003.03590.x

Journet, L., Agrain, C., Broz, P., and Cornelis, G. R. (2003). The needle length of bacterial injectisomes is determined by a molecular ruler. Science 302, 1757-1760. doi: 10.1126/science.1091422

Kawagishi, I., Homma, M., Williams, A. W., and Macnab, R. M. (1996). Characterization of the flagellar hook length control protein fliK of Salmonella typhimurium and Escherichia coli. J. Bacteriol. 178, 2954-2959.

Kenjale, R., Wilson, J., Zenk, S. F., Saurya, S., Picking, W. L., Picking, W. D., et al. (2005). The needle component of the type III secreton of Shigella regulates the activity of the secretion apparatus. J. Biol. Chem. 280, 42929-42937. doi: 10.1074/jbc.M508377200

Kenny, B., Abe, A., Stein, M., and Finlay, B. B. (1997a). Enteropathogenic Escherichia coli protein secretion is induced in response to conditions similar to those in the gastrointestinal tract. Infect. Immun. 65, 2606-2612.

Kenny, B., DeVinney, R., Stein, M., Reinscheid, D. J., Frey, E. A., and Finlay, B. B. (1997b). Enteropathogenic E. coli (EPEC) transfers its receptor for intimate adherence into mammalian cells. Cell 91, 511-520.

Kenny, B., and Finlay, B. B. (1997). Intimin-dependent binding of enteropathogenic Escherichia coli to host cells triggers novel signaling events, including tyrosine phosphorylation of phospholipase C-gamma1. Infect. Immun. 65, 2528-2536.

Kimbrough, T. G., and Miller, S. I. (2000). Contribution of Salmonella typhimurium type III secretion components to needle complex formation. Proc. Natl. Acad. Sci. U.S.A. 97, 11008-11013. doi: 10.1073/pnas.200209497

Kimura, K., Iwatsuki, M., Nagai, T., Matsumoto, A., Takahashi, Y., Shiomi, K., et al. (2011). A small-molecule inhibitor of the bacterial type III secretion system protects against in vivo infection with Citrobacter rodentium. J. Antibiot. 64, 197-203. doi: 10.1038/ja.2010.155

Kinoshita, M., Hara, N., Imada, K., Namba, K., and Minamino, T. (2013). Interactions of bacterial flagellar chaperone-substrate complexes with FlhA contribute to co-ordinating assembly of the flagellar filament. Mol. Microbiol. 90, 1249-1261. doi: 10.1111/mmi.12430

Knutton, S., Baldwin, T., Williams, P. H., and McNeish, A. S. (1989). Actin accumulation at sites of bacterial adhesion to tissue culture cells: basis of a new diagnostic test for enteropathogenic and enterohemorrhagic Escherichia coli. Infect. Immun. 57, 1290-1298.

Knutton, S., Rosenshine, I., Pallen, M. J., Nisan, I., Neves, B. C., Bain, C. et al. (1998). A novel EspA-associated surface organelle of enteropathogenic Escherichia coli involved in protein translocation into epithelial cells. EMBO J. 17, 2166-2176. doi: 10.1093/emboj/17.8.2166

Kodama, T., Akeda, Y., Kono, G., Takahashi, A., Imura, K., Iida, T., et al. (2002). The EspB protein of enterohaemorrhagic Escherichia coli interacts directly with alpha-catenin. Cell. Microbiol. 4, 213-222. doi: 10.1046/j.14625822.2002.00176.x

Kotloff, K. L., Nataro, J. P., Blackwelder, W. C., Nasrin, D., Farag, T. H., Panchalingam, S., et al. (2013). Burden and aetiology of diarrhoeal disease in infants and young children in developing countries (the Global Enteric Multicenter Study, GEMS): a prospective, case-control study. Lancet 382, 209-222. doi: 10.1016/S0140-6736(13)60844-2

Kowal, J., Chami, M., Ringler, P., Müller, S. A., Kudryashev, M., CastañoDíez, D., et al. (2013). Structure of the dodecameric Yersinia enterocolitica secretin YscC and its trypsin-resistant core. Structure 21, 2152-2161. doi: 10.1016/j.str.2013.09.012

Kresse, A. U., Beltrametti, F., Müller, A., Ebel, F., and Guzmán, C. A. (2000). Characterization of SepL of enterohemorrhagic Escherichia coli. J. Bacteriol. 182, 6490-6498. doi: 10.1128/JB.182.22.6490-6498.2000

Kresse, A. U., Rohde, M., and Guzmán, C. A. (1999). The EspD protein of enterohemorrhagic Escherichia coli is required for the formation of bacterial surface appendages and is incorporated in the cytoplasmic membranes of target cells. Infect. Immun. 67, 4834-4842.

Kresse, A. U., Schulze, K., Deibel, C., Ebel, F., Rohde, M., Chakraborty, T. et al. (1998). Pas, a novel protein required for protein secretion and attaching 
and effacing activities of enterohemorrhagic Escherichia coli. J. Bacteriol. 180, 4370-4379.

Kubori, T., and Galán, J. E. (2002). Salmonella type III secretion-associated protein InvE controls translocation of effector proteins into host cells. J. Bacteriol. 184, 4699-4708. doi: 10.1128/JB.184.17.4699-4708.2002

Kubori, T., Matsushima, Y., Nakamura, D., Uralil, J., Lara-Tejero, M., Sukhan, A., et al. (1998). Supramolecular structure of the Salmonella typhimurium type III protein secretion system. Science 280, 602-605.

Kubori, T., Sukhan, A., Aizawa, S. I., and Galán, J. E. (2000). Molecular characterization and assembly of the needle complex of the Salmonella typhimurium type III protein secretion system. Proc. Natl. Acad. Sci. U.S.A. 97, 10225-10230. doi: 10.1073/pnas.170128997

Ku, C. P., Lio, J. C., Wang, S. H., Lin, C. N., and Syu, W. J. (2009). Identification of a third EspA-binding protein that forms part of the type III secretion system of enterohemorrhagic Escherichia coli. J. Biol. Chem. 284, 1686-1693. doi: 10.1074/jbc.M807478200

Kudryashev, M., Stenta, M., Schmelz, S., Amstutz, M., Wiesand, U., CastañoDíez, D., et al. (2013). In situ structural analysis of the Yersinia enterocolitica injectisome. Elife 2:e00792. doi: 10.7554/eLife.00792

Kutsukake, K., Minamino, T., and Yokoseki, T. (1994). Isolation and characterization of FliK-independent flagellation mutants from Salmonella typhimurium. J. Bacteriol. 176, 7625-7629.

Lai, L. C., Wainwright, L. A., Stone, K. D., and Donnenberg, M. S. (1997). A third secreted protein that is encoded by the enteropathogenic Escherichia coli pathogenicity island is required for transduction of signals and for attaching and effacing activities in host cells. Infect. Immun. 65, 2211-2217.

Lara-Tejero, M., Kato, J., Wagner, S., Liu, X., and Galán, J. E. (2011). A sorting platform determines the order of protein secretion in bacterial type III systems. Science 331, 1188-1191. doi: 10.1126/science.1201476

Larzábal, M., Mercado, E. C., Vilte, D. A., Salazar-González, H., Cataldi, A., and Navarro-Garcia, F. (2010). Designed coiled-coil peptides inhibit the type three secretion system of enteropathogenic Escherichia coli. PLOS ONE 5:e9046. doi: 10.1371/journal.pone.0009046

Lavander, M., Sundberg, L., Edqvist, P. J., Lloyd, S. A., Wolf-Watz, H., and Forsberg, A. (2002). Proteolytic cleavage of the FlhB homologue YscU of Yersinia pseudotuberculosis is essential for bacterial survival but not for type III secretion. J. Bacteriol. 184, 4500-4509. doi: 10.1128/JB.184.16.4500-45 09.2002

Lee, P. C., and Rietsch, A. (2015). Fueling type III secretion. Trends Microbiol. 23, 296-300. doi: 10.1016/j.tim.2015.01.012

Lee, P. C., Zmina, S. E., Stopford, C. M., Toska, J., and Rietsch, A. (2014). Control of type III secretion activity and substrate specificity by the cytoplasmic regulator PcrG. Proc. Natl. Acad. Sci. U.S.A. 111, E2027-E2036. doi: $10.1073 /$ pnas.1402658111

Lefebre, M. D., and Galán, J. E. (2014). The inner rod protein controls substrate switching and needle length in a Salmonella type III secretion system. Proc. Natl. Acad. Sci. U.S.A. 111, 817-822. doi: 10.1073/pnas.1319698111

Leuko, S., and Raivio, T. L. (2012). Mutations that impact the enteropathogenic Escherichia coli Cpx envelope stress response attenuate virulence in Galleria mellonella. Infect. Immun. 80, 3077-3085. doi: 10.1128/IAI. 00081-12

Levenson, R., Zhou, H., and Dahlquist, F. W. (2012). Structural insights into the interaction between the bacterial flagellar motor proteins FliF and FliG. Biochemistry 51, 5052-5060. doi: 10.1021/bi3004582

Levine, J. A., Hansen, A. M., Michalski, J. M., Hazen, T. H., Rasko, D. A., and Kaper, J. B. (2014). H-NST induces LEE expression and the formation of attaching and effacing lesions in enterohemorrhagic Escherichia coli. PLoS ONE 9:e86618. doi: 10.1371/journal.pone.0086618

Lilic, M., Quezada, C. M., and Stebbins, C. E. (2010). A conserved domain in type III secretion links the cytoplasmic domain of InvA to elements of the basal body. Acta Crystallogr. D. Biol. Crystallogr. 66(Pt 6), 709-713. doi: 10.1107/S0907444910010796

Lilic, M., Vujanac, M., and Stebbins, C. E. (2006). A common structural motif in the binding of virulence factors to bacterial secretion chaperones. Mol. Cell 21, 653-664. doi: 10.1016/j.molcel.2006.01.026

Lin, C. N., Sun, W. S., Lu, H. Y., Ng, S. C., Liao, Y. S., and Syu, W. J. (2014). Protein interactions and regulation of EscA in enterohemorrhagic E. coli. PLoS ONE 9:e85354. doi: 10.1371/journal.pone.0085354
Loquet, A., Sgourakis, N. G., Gupta, R., Giller, K., Riedel, D., Goosmann, C., et al. (2012). Atomic model of the type III secretion system needle. Nature 486, 276-279. doi: 10.1038/nature11079

Lorenz, C., and Büttner, D. (2011). Secretion of early and late substrates of the type III secretion system from Xanthomonas is controlled by $\mathrm{HpaC}$ and the C-terminal domain of HrcU. Mol. Microbiol. 79, 447-467. doi: 10.1111/j.13652958.2010.07461.x

Lorenz, C., Hausner, J., and Büttner, D. (2012). HrcQ provides a docking site for early and late type III secretion substrates from Xanthomonas. PLoS ONE 7:e51063. doi: 10.1371/journal.pone.0051063

Lorenz, C., Schulz, S., Wolsch, T., Rossier, O., Bonas, U., and Büttner, D. (2008). $\mathrm{HpaC}$ controls substrate specificity of the Xanthomonas type III secretion system. PLoS Pathog. 4:e1000094. doi: 10.1371/journal.ppat.1000094

Lountos, G. T., Austin, B. P., Nallamsetty, S., and Waugh, D. S. (2009). Atomic resolution structure of the cytoplasmic domain of Yersinia pestis $\mathrm{YscU}$, a regulatory switch involved in type III secretion. Protein Sci. 18, 467-474. doi: $10.1002 /$ pro. 56

Luo, W., and Donnenberg, M. S. (2011). Interactions and predicted host membrane topology of the enteropathogenic Escherichia coli translocator protein EspB. J. Bacteriol. 193, 2972-2980. doi: 10.1128/JB.00153-11

Luo, Y., Bertero, M. G., Frey, E. A., Pfuetzner, R. A., Wenk, M. R., Creagh, L., et al. (2001). Structural and biochemical characterization of the type III secretion chaperones CesT and SigE. Nat. Struct. Biol. 8, 1031-1036. doi: 10.1038/ nsb717

Magdalena, J., Hachani, A., Chamekh, M., Jouihri, N., Gounon, P., Blocker, A., et al. (2002). Spa32 regulates a switch in substrate specificity of the type III secreton of Shigella flexneri from needle components to Ipa proteins. J. Bacteriol. 184, 3433-3441. doi: 10.1128/JB.184.13.3433-3441.2002

Marlovits, T. C., Kubori, T., Lara-Tejero, M., Thomas, D., Unger, V. M., and Galán, J. E. (2006). Assembly of the inner rod determines needle length in the type III secretion injectisome. Nature 441, 637-640. doi: 10.1038/nature 04822

Marlovits, T. C., Kubori, T., Sukhan, A., Thomas, D. R., Galán, J. E., and Unger, V. M. (2004). Structural insights into the assembly of the type III secretion needle complex. Science 306, 1040-1042. doi: 10.1126/science.1102610

Martinez-Argudo, I., and Blocker, A. J. (2010). The Shigella T3SS needle transmits a signal for MxiC release, which controls secretion of effectors. Mol. Microbiol. 78, 1365-1378. doi: 10.1111/j.1365-2958.2010.07413.x

Marykwas, D. L., Schmidt, S. A., and Berg, H. C. (1996). Interacting components of the flagellar motor of Escherichia coli revealed by the two-hybrid system in yeast. J. Mol. Biol. 256, 564-576. doi: 10.1006/jmbi.1996.0109

McDaniel, T. K., Jarvis, K. G., Donnenberg, M. S., and Kaper, J. B. (1995). A genetic locus of enterocyte effacement conserved among diverse enterobacterial pathogens. Proc. Natl. Acad. Sci. U.S.A. 92, 1664-1668.

McDaniel, T. K., and Kaper, J. B. (1997). A cloned pathogenicity island from enteropathogenic Escherichia coli confers the attaching and effacing phenotype on E. coli K-12. Mol. Microbiol. 23, 399-407.

McDowell, M. A., Marcoux, J., McVicker, G., Johnson, S., Fong, Y. H., Stevens, R., et al. (2016). Characterisation of Shigella Spa33 and Thermotoga FliM/N reveals a new model for C-ring assembly in T3SS. Mol. Microbiol. 99, 749-766. doi: $10.1111 / \mathrm{mmi} .13267$

Medhekar, B., Shrivastava, R., Mattoo, S., Gingery, M., and Miller, J. F. (2009). Bordetella Bsp22 forms a filamentous type III secretion system tip complex and is immunoprotective in vitro and in vivo. Mol. Microbiol. 71, 492-504. doi: 10.1111/j.1365-2958.2008.06543.x

Mellies, J. L., Elliott, S. J., Sperandio, V., Donnenberg, M. S., and Kaper, J. B. (1999). The Per regulon of enteropathogenic Escherichia coli: identification of a regulatory cascade and a novel transcriptional activator, the locus of enterocyte effacement (LEE)-encoded regulator (Ler). Mol. Microbiol. 33, 296-306.

Mills, E., Baruch, K., Aviv, G., Nitzan, M., and Rosenshine, I. (2013). Dynamics of the type III secretion system activity of enteropathogenic Escherichia coli. MBio 4:e00303-13. doi: 10.1128/mBio.00303-13

Mills, E., Baruch, K., Charpentier, X., Kobi, S., and Rosenshine, I. (2008). Real-time analysis of effector translocation by the type III secretion system of enteropathogenic Escherichia coli. Cell Host Microbe 3, 104-113. doi: 10.1016/j.chom.2007.11.007

Milon, A., Oswald, E., and De Rycke, J. (1999). Rabbit EPEC: a model for the study of enteropathogenic Escherichia coli. Vet. Res. 30, 203-219. 
Minamino, T. (2014). Protein export through the bacterial flagellar type III export pathway. Biochim. Biophys. Acta 1843, 1642-1648. doi: 10.1016/ j.bbamcr.2013.09.005

Minamino, T., González-Pedrajo, B., Yamaguchi, K., Aizawa, S. I., and Macnab, R. M. (1999). FliK, the protein responsible for flagellar hook length control in Salmonella, is exported during hook assembly. Mol. Microbiol. 34, 295-304.

Minamino, T., Kinoshita, M., Hara, N., Takeuchi, S., Hida, A., Koya, S., et al. (2012). Interaction of a bacterial flagellar chaperone FlgN with FlhA is required for efficient export of its cognate substrates. Mol. Microbiol. 83, 775-788. doi: 10.1111/j.1365-2958.2011.07964.x

Minamino, T., and Macnab, R. M. (2000a). Domain structure of Salmonella FlhB, a flagellar export component responsible for substrate specificity switching. J. Bacteriol. 182, 4906-4914. doi: 10.1128/JB.182.17.4906-4914.2000

Minamino, T., and MacNab, R. M. (2000b). FliH, a soluble component of the type III flagellar export apparatus of Salmonella, forms a complex with FliI and inhibits its ATPase activity. Mol. Microbiol. 37, 1494-1503. doi: 10.1046/j.13652958.2000.02106.x

Minamino, T., Morimoto, Y. V., Hara, N., and Namba, K. (2011). An energy transduction mechanism used in bacterial flagellar type III protein export. Nat. Commun. 2, 475. doi: 10.1038/ncomms1488

Minamino, T., and Namba, K. (2008). Distinct roles of the FliI ATPase and proton motive force in bacterial flagellar protein export. Nature 451, 485-488. doi: 10.1038/nature 06449

Minamino, T., Saijo-Hamano, Y., Furukawa, Y., González-Pedrajo, B., Macnab, R. M., and Namba, K. (2004). Domain organization and function of Salmonella FliK, a flagellar hook-length control protein. J. Mol. Biol. 341, 491-502. doi: 10.1016/j.jmb.2004.06.012

Minamino, T., Shimada, M., Okabe, M., Saijo-Hamano, Y., Imada, K., Kihara, M., et al. (2010). Role of the C-terminal cytoplasmic domain of FlhA in bacterial flagellar type III protein export. J. Bacteriol. 192, 1929-1936. doi: 10.1128/JB.01328-09

Monjarás Feria, J., García-Gómez, E., Espinosa, N., Minamino, T., Namba, K., and González-Pedrajo, B. (2012). Role of EscP (Orf16) in injectisome biogenesis and regulation of type III protein secretion in enteropathogenic Escherichia coli. J. Bacteriol. 194, 6029-6045. doi: 10.1128/JB.01215-12

Monjarás Feria, J. V., Lefebre, M. D., Stierhof, Y. D., Galán, J. E., and Wagner, S. (2015). Role of autocleavage in the function of a type III secretion specificity switch protein in Salmonella enterica serovar Typhimurium. MBio 6:e01459-15. doi: 10.1128/mBio.01459-15

Moon, H. W., Whipp, S. C., Argenzio, R. A., Levine, M. M., and Giannella, R. A. (1983). Attaching and effacing activities of rabbit and human enteropathogenic Escherichia coli in pig and rabbit intestines. Infect. Immun. 41, 1340-1351.

Moore, S. A., and Jia, Y. (2010). Structure of the cytoplasmic domain of the flagellar secretion apparatus component FlhA from Helicobacter pylori. J. Biol. Chem. 285, 21060-21069. doi: 10.1074/jbc.M110.119412

Moraes, T. F., Spreter, T., and Strynadka, N. C. (2008). Piecing together the type III injectisome of bacterial pathogens. Curr. Opin. Struct. Biol. 18, 258-266. doi: 10.1016/j.sbi.2007.12.011

Moreira, C. G., Palmer, K., Whiteley, M., Sircili, M. P., Trabulsi, L. R., Castro, A. F., et al. (2006). Bundle-forming pili and EspA are involved in biofilm formation by enteropathogenic Escherichia coli. J. Bacteriol. 188, 3952-3961. doi: 10.1128/JB.00177-06

Morita-Ishihara, T., Ogawa, M., Sagara, H., Yoshida, M., Katayama, E., and Sasakawa, C. (2006). Shigella Spa33 is an essential C-ring component of type III secretion machinery. J. Biol. Chem. 281, 599-607. doi: 10.1074/jbc.M50 9644200

Moriya, N., Minamino, T., Hughes, K. T., Macnab, R. M., and Namba, K. (2006). The type III flagellar export specificity switch is dependent on FliK ruler and a molecular clock. J. Mol. Biol. 359, 466-477. doi: 10.1016/j.jmb.2006. 03.025

Morris, D. P., Roush, E. D., Thompson, J. W., Moseley, M. A., Murphy, J. W., and McMurry, J. L. (2010). Kinetic characterization of Salmonella FliKFlhB interactions demonstrates complexity of the Type III secretion substratespecificity switch. Biochemistry 49, 6386-6393. doi: 10.1021/bi100487p

Mundy, R., MacDonald, T. T., Dougan, G., Frankel, G., and Wiles, S. (2005). Citrobacter rodentium of mice and man. Cell. Microbiol. 7, 1697-1706. doi: 10.1111/j.1462-5822.2005.00625.x
Mundy, R., Pickard, D., Wilson, R. K., Simmons, C. P., Dougan, G., and Frankel, G. (2003). Identification of a novel type IV pilus gene cluster required for gastrointestinal colonization of Citrobacter rodentium. Mol. Microbiol. 48, 795-809. doi: 10.1046/j.1365-2958.2003.03470.x

Munera, D., Crepin, V. F., Marches, O., and Frankel, G. (2010). N-terminal type III secretion signal of enteropathogenic Escherichia coli translocator proteins. J. Bacteriol. 192, 3534-3539. doi: 10.1128/JB.00046-10

Nans, A., Kudryashev, M., Saibil, H. R., and Hayward, R. D. (2015). Structure of a bacterial type III secretion system in contact with a host membrane in situ. Nat. Commun. 6:10114. doi: 10.1038/ncomms10114

Nataro, J. P., and Kaper, J. B. (1998). Diarrheagenic Escherichia coli. Clin. Microbiol. Rev. 11, 142-201.

Neves, B. C., Mundy, R., Petrovska, L., Dougan, G., Knutton, S., and Frankel, G. (2003). CesD2 of enteropathogenic Escherichia coli is a second chaperone for the type III secretion translocator protein EspD. Infect. Immun. 71, 2130-2141. doi: 10.1128/IAI.71.4.2130-2141.2003

Notti, R. Q., Bhattacharya, S., Lilic, M., and Stebbins, C. E. (2015). A common assembly module in injectisome and flagellar type III secretion sorting platforms. Nat. Commun. 6, 7125. doi: 10.1038/ncomms 8125

Notti, R. Q., and Stebbins, C. E. (2016). The structure and function of Type III secretion systems. Microbiol. Spectr. 4:VMBF-0004-2015. doi: 10.1128/microbiolspec.VMBF-0004-2015

O'Connell, C. B., Creasey, E. A., Knutton, S., Elliott, S., Crowther, L. J., Luo, W., et al. (2004). SepL, a protein required for enteropathogenic Escherichia coli type III translocation, interacts with secretion component SepD. Mol. Microbiol. 52, 1613-1625. doi: 10.1111/j.1365-2958.2004.04101.x

Ogino, T., Ohno, R., Sekiya, K., Kuwae, A., Matsuzawa, T., Nonaka, T., et al. (2006). Assembly of the type III secretion apparatus of enteropathogenic Escherichia coli. J. Bacteriol. 188, 2801-2811. doi: 10.1128/JB.188.8.2801-2811.2006

Padavannil, A., Jobichen, C., Mills, E., Velazquez-Campoy, A., Li, M., Leung, K. Y., et al. (2013). Structure of GrlR-GrlA complex that prevents GrlA activation of virulence genes. Nat. Commun. 4, 2546. doi: 10.1038/ncomms3546

Page, A. L., and Parsot, C. (2002). Chaperones of the type III secretion pathway: jacks of all trades. Mol. Microbiol. 46, 1-11. doi: 10.1046/j.13652958.2002.03138.x

Pallen, M., Chaudhuri, R., and Khan, A. (2002). Bacterial FHA domains: neglected players in the phospho-threonine signalling game? Trends Microbiol. 10, 556-563. doi: 10.1016/S0966-842X(02)02476-9

Pallen, M. J., Bailey, C. M., and Beatson, S. A. (2006). Evolutionary links between FliH/YscL-like proteins from bacterial type III secretion systems and secondstalk components of the FoF1 and vacuolar ATPases. Protein Sci. 15, 935-941. doi: $10.1110 /$ ps.051958806

Pallen, M. J., Beatson, S. A., and Bailey, C. M. (2005). Bioinformatics analysis of the locus for enterocyte effacement provides novel insights into type-III secretion. BMC Microbiol. 5:9. doi: 10.1186/1471-2180-5-9

Pan, N., Lee, C., and Goguen, J. (2007). High throughput screening for smallmolecule inhibitors of type III secretion in Yersinia pestis. Adv. Exp. Med. Biol. 603, 367-375. doi: 10.1007/978-0-387-72124-8_34

Parsot, C., Hamiaux, C., and Page, A. L. (2003). The various and varying roles of specific chaperones in type III secretion systems. Curr. Opin. Microbiol. 6, 7-14. doi: 10.1016/S1369-5274(02)00002-4

Payne, P. L., and Straley, S. C. (1999). YscP of Yersinia pestis is a secreted component of the Yop secretion system. J. Bacteriol. 181, 2852-2862.

Perna, N. T., Mayhew, G. F., Pósfai, G., Elliott, S., Donnenberg, M. S., Kaper, J. B., et al. (1998). Molecular evolution of a pathogenicity island from enterohemorrhagic Escherichia coli O157:H7. Infect. Immun. 66, 3810-3817.

Petty, N. K., Bulgin, R., Crepin, V. F., Cerdeño-Tárraga, A. M., Schroeder, G. N., Quail, M. A., et al. (2010). The Citrobacter rodentium genome sequence reveals convergent evolution with human pathogenic Escherichia coli. J. Bacteriol. 192, 525-538. doi: 10.1128/JB.01144-09

Phillips, A. D., Navabpour, S., Hicks, S., Dougan, G., Wallis, T., and Frankel, G. (2000). Enterohaemorrhagic Escherichia coli O157:H7 target Peyer's patches in humans and cause attaching/effacing lesions in both human and bovine intestine. Gut 47, 377-381. doi: 10.1136/gut.47.3.377

Portaliou, A. G., Tsolis, K. C., Loos, M. S., Zorzini, V., and Economou, A. (2016). Type III secretion: building and operating a remarkable Nanomachine. Trends Biochem. Sci. 41, 175-189. doi: 10.1016/j.tibs.2015.09.005 
Radics, J., Königsmaier, L., and Marlovits, T. C. (2014). Structure of a pathogenic type 3 secretion system in action. Nat. Struct. Mol. Biol. 21, 82-87. doi: $10.1038 /$ nsmb. 2722

Ramu, T., Prasad, M. E., Connors, E., Mishra, A., Thomassin, J. L., Leblanc, J., et al. (2013). A novel C-terminal region within the multicargo type III secretion chaperone CesT contributes to effector secretion. J. Bacteriol. 195, 740-756. doi: 10.1128/JB.01967-12

Rendón, M. A., Saldaña, Z., Erdem, A. L., Monteiro-Neto, V., Vázquez, A., Kaper, J. B., et al. (2007). Commensal and pathogenic Escherichia coli use a common pilus adherence factor for epithelial cell colonization. Proc. Natl. Acad. Sci. U.S.A. 104, 10637-10642. doi: 10.1073/pnas.0704104104

Riff, J. D., Callahan, J. W., and Sherman, P. M. (2005). Cholesterol-enriched membrane microdomains are required for inducing host cell cytoskeleton rearrangements in response to attaching-effacing Escherichia coli. Infect. Immun. 73, 7113-7125. doi: 10.1128/IAI.73.11.7113-7125.2005

Riley, L. W., Remis, R. S., Helgerson, S. D., McGee, H. B., Wells, J. G., Davis, B. R., et al. (1983). Hemorrhagic colitis associated with a rare Escherichia coli serotype. N. Engl. J. Med. 308, 681-685. doi: 10.1056/NEJM198303243081203

Romo-Castillo, M., Andrade, A., Espinosa, N., Monjáras Feria, J., Soto, E., DíazGuerrero, M., et al. (2014). EscO, a functional and structural analog of the flagellar FliJ protein, is a positive regulator of $\mathrm{EscN}$ ATPase activity of the enteropathogenic Escherichia coli injectisome. J. Bacteriol. 196, 2227-2241. doi: 10.1128/JB.01551-14

Ross, J. A., and Plano, G. V. (2011). A C-terminal region of Yersinia pestis YscD binds the outer membrane secretin YscC. J. Bacteriol. 193, 2276-2289. doi: 10.1128/JB.01137-10

Ruano-Gallego, D., Álvarez, B., and Fernández, L. Á. (2015). Engineering the controlled assembly of Filamentous Injectisomes in E. coli K-12 for Protein Translocation into Mammalian Cells. ACS Synth. Biol. 4, 1030-1041. doi: 10.1021/acssynbio.5b00080

Saijo-Hamano, Y., Imada, K., Minamino, T., Kihara, M., Shimada, M., Kitao, A., et al. (2010). Structure of the cytoplasmic domain of FlhA and implication for flagellar type III protein export. Mol. Microbiol. 76, 260-268. doi: 10.1111/j.1365-2958.2010.07097.x

Saldana, Z., Erdem, A. L., Schuller, S., Okeke, I. N., Lucas, M., Sivananthan, A., et al. (2009). The Escherichia coli common pilus and the bundle-forming pilus act in concert during the formation of localized adherence by enteropathogenic E. coli. J. Bacteriol. 191, 3451-3461. doi: 10.1128/JB.01539-08

Sal-Man, N., Biemans-Oldehinkel, E., Sharon, D., Croxen, M. A., Scholz, R., Foster, L. J., et al. (2012a). EscA is a crucial component of the type III secretion system of enteropathogenic Escherichia coli. J. Bacteriol. 194, 2819-2828. doi: 10.1128/JB.00103-12

Sal-Man, N., Deng, W., and Finlay, B. B. (2012b). EscI: a crucial component of the type III secretion system forms the inner rod structure in enteropathogenic Escherichia coli. Biochem. J. 442, 119-125. doi: 10.1042/BJ201 11620

Sal-Man, N., Setiaputra, D., Scholz, R., Deng, W., Yu, A. C., Strynadka, N. C., et al. (2013). EscE and EscG are cochaperones for the type III needle protein EscF of enteropathogenic Escherichia coli. J. Bacteriol. 195, 2481-2489. doi: 10.1128/JB.00118-13

Sánchez-SanMartín, C., Bustamante, V. H., Calva, E., and Puente, J. L. (2001). Transcriptional regulation of the orf19 gene and the tir-cesT-eae operon of enteropathogenic Escherichia coli. J. Bacteriol. 183, 2823-2833. doi: 10.1128/JB.183.9.2823-2833.2001

Santos, A. S., and Finlay, B. B. (2015). Bringing down the host: enteropathogenic and enterohaemorrhagic Escherichia coli effector-mediated subversion of host innate immune pathways. Cell. Microbiol. 17, 318-332. doi: 10.1111/ cmi. 12412

Schauer, D. B., and Falkow, S. (1993). Attaching and effacing locus of a Citrobacter freundii biotype that causes transmissible murine colonic hyperplasia. Infect. Immun. 61, 2486-2492.

Schmidt, H., and Hensel, M. (2004). Pathogenicity islands in bacterial pathogenesis. Clin. Microbiol. Rev. 17, 14-56. doi: 10.1128/CMR.17.1.1456.2004

Schraidt, O., Lefebre, M. D., Brunner, M. J., Schmied, W. H., Schmidt, A., Radics, J., et al. (2010). Topology and organization of the Salmonella typhimurium type III secretion needle complex components. PLoS Pathog. 6:e1000824. doi: 10.1371/journal.ppat.1000824
Schraidt, O., and Marlovits, T. C. (2011). Three-dimensional model of Salmonella's needle complex at subnanometer resolution. Science 331, 1192-1195. doi: 10.1126/science. 1199358

Schubot, F. D., Jackson, M. W., Penrose, K. J., Cherry, S., Tropea, J. E., Plano, G. V., et al. (2005). Three-dimensional structure of a macromolecular assembly that regulates type III secretion in Yersinia pestis. J. Mol. Biol. 346, 1147-1161. doi: 10.1016/j.jmb.2004.12.036

Schuch, R., and Maurelli, A. T. (2001). MxiM and MxiJ, base elements of the Mxi-Spa type III secretion system of Shigella, interact with and stabilize the MxiD secretin in the cell envelope. J. Bacteriol. 183, 6991-6998. doi: 10.1128/JB.183.24.6991-6998.2001

Schulz, S., and Büttner, D. (2011). Functional characterization of the type III secretion substrate specificity switch protein $\mathrm{HpaC}$ from Xanthomonas campestris pv. vesicatoria. Infect. Immun. 79, 2998-3011. doi: 10.1128/IAI.00180-11

Sekiya, K., Ohishi, M., Ogino, T., Tamano, K., Sasakawa, C., and Abe, A. (2001). Supermolecular structure of the enteropathogenic Escherichia coli type III secretion system and its direct interaction with the EspA-sheath-like structure. Proc. Natl. Acad. Sci. U.S.A. 98, 11638-11643. doi: 10.1073/pnas.191378598

Shaikh, T. R., Thomas, D. R., Chen, J. Z., Samatey, F. A., Matsunami, H., Imada, K., et al. (2005). A partial atomic structure for the flagellar hook of Salmonella typhimurium. Proc. Natl. Acad. Sci. U.S.A. 102, 1023-1028. doi: 10.1073/pnas.0409020102

Shaw, R. K., Daniell, S., Ebel, F., Frankel, G., and Knutton, S. (2001). EspA filamentmediated protein translocation into red blood cells. Cell. Microbiol. 3, 213-222. doi: 10.1046/j.1462-5822.2001.00105.x

Shaw, R. K., Smollett, K., Cleary, J., Garmendia, J., Straatman-Iwanowska, A., Frankel, G., et al. (2005). Enteropathogenic Escherichia coli type III effectors EspG and EspG2 disrupt the microtubule network of intestinal epithelial cells. Infect. Immun. 73, 4385-4390. doi: 10.1128/IAI.73.7.4385-4390.2005

Shen, D. K., and Blocker, A. J. (2016). MxiA, MxiC and IpaD regulate substrate selection and secretion mode in the T3SS of Shigella flexneri. PLoS One 11:e0155141. doi: 10.1371/journal.pone.0155141

Shen, D. K., Moriya, N., Martinez-Argudo, I., and Blocker, A. J. (2012). Needle length control and the secretion substrate specificity switch are only loosely coupled in the type III secretion apparatus of Shigella. Microbiology 158(Pt 7), 1884-1896. doi: 10.1099/mic.0.059618-0

Shen, L., Macnaughtan, M. A., Frohlich, K. M., Cong, Y., Goodwin, O. Y., Chou, C. W., et al. (2015). Multipart chaperone-effector recognition in the Type III secretion system of Chlamydia trachomatis. J. Biol. Chem. 290, 28141-28155. doi: 10.1074/jbc.M115.670232

Shibata, S., Takahashi, N., Chevance, F. F., Karlinsey, J. E., Hughes, K. T., and Aizawa, S. (2007). FliK regulates flagellar hook length as an internal ruler. Mol. Microbiol. 64, 1404-1415. doi: 10.1111/j.1365-2958.2007.05750.x

Silva-Herzog, E., Joseph, S. S., Avery, A. K., Coba, J. A., Wolf, K., Fields, K. A., et al. (2011). Scc1 (CP0432) and Scc4 (CP0033) function as a type III secretion chaperone for CopN of Chlamydia pneumoniae. J. Bacteriol. 193, 3490-3496. doi: 10.1128/JB.00203-11

Smith, T. G., Pereira, L., and Hoover, T. R. (2009). Helicobacter pylori FlhB processing-deficient variants affect flagellar assembly but not flagellar gene expression. Microbiology 155(Pt 4), 1170-1180. doi: 10.1099/mic.0.0 22806-0

Sorg, I., Wagner, S., Amstutz, M., Müller, S. A., Broz, P., Lussi, Y., et al. (2007). $\mathrm{Ysc} \mathrm{U}$ recognizes translocators as export substrates of the Yersinia injectisome. EMBO J. 26, 3015-3024. doi: 10.1038/sj.emboj.7601731

Spinale, J. M., Ruebner, R. L., Copelovitch, L., and Kaplan, B. S. (2013). Longterm outcomes of Shiga toxin hemolytic uremic syndrome. Pediatr. Nephrol. 28, 2097-2105. doi: 10.1007/s00467-012-2383-6

Spreter, T., Yip, C. K., Sanowar, S., André, I., Kimbrough, T. G., Vuckovic, M., et al. (2009). A conserved structural motif mediates formation of the periplasmic rings in the type III secretion system. Nat. Struct. Mol. Biol. 16, 468-476. doi: $10.1038 /$ nsmb. 1603

Stainier, I., Bleves, S., Josenhans, C., Karmani, L., Kerbourch, C., Lambermont, I., et al. (2000). YscP, a Yersinia protein required for Yop secretion that is surface exposed, and released in low Ca2+. Mol. Microbiol. 37, 1005-1018. doi: 10.1046/j.1365-2958.2000.02026.x

Stone, C. B., Bulir, D. C., Emdin, C. A., Pirie, R. M., Porfilio, E. A., Slootstra, J. W., et al. (2011). Chlamydia pneumoniae CdsL regulates CdsN ATPase activity, 
and disruption with a Peptide Mimetic Prevents Bacterial invasion. Front. Microbiol. 2:21. doi: 10.3389/fmicb.2011.00021

Su, C., and Brandt, L. J. (1995). Escherichia coli O157:H7 infection in humans. Ann. Intern. Med. 123, 698-714.

Su, M. S., Kao, H. C., Lin, C. N., and Syu, W. J. (2008). Gene 10017 encodes a second chaperone for EspA of enterohaemorrhagic Escherichia coli O157: H7. Microbiology 154(Pt 4), 1094-1103. doi: 10.1099/mic.0.2007/013946-0

Sukhan, A., Kubori, T., and Galán, J. E. (2003). Synthesis and localization of the Salmonella SPI-1 type III secretion needle complex proteins PrgI and PrgJ. J. Bacteriol. 185, 3480-3483. doi: 10.1128/JB.185.11.3480-3483.2003

Sukhan, A., Kubori, T., Wilson, J., and Galán, J. E. (2001). Genetic analysis of assembly of the Salmonella enterica serovar Typhimurium type III secretion-associated needle complex. J. Bacteriol. 183, 1159-1167. doi: 10.1128/JB.183.4.1159-1167.2001

Sun, W. S., Chen, J. W., Wu, Y. C., Tsai, H. Y., Kuo, Y. L., and Syu, W. J. (2016). Expression regulation of Polycistronic lee3 genes of Enterohaemorrhagic Escherichia coli. PLoS ONE 11:e0155578. doi: 10.1371/journal.pone. 0155578

Tamano, K., Aizawa, S., Katayama, E., Nonaka, T., Imajoh-Ohmi, S., Kuwae, A., et al. (2000). Supramolecular structure of the Shigella type III secretion machinery: the needle part is changeable in length and essential for delivery of effectors. EMBO J. 19, 3876-3887. doi: 10.1093/emboj/19.15.3876

Tamano, K., Katayama, E., Toyotome, T., and Sasakawa, C. (2002). Shigella Spa32 is an essential secretory protein for functional type III secretion machinery and uniformity of its needle length. J. Bacteriol. 184, 1244-1252. doi: 10.1128/JB.184.5.1244-1252.2002

Tarr, P. I., Gordon, C. A., and Chandler, W. L. (2005). Shiga-toxin-producing Escherichia coli and haemolytic uraemic syndrome. Lancet 365, 1073-1086. doi: 10.1016/S0140-6736(05)71144-2

Taylor, K. A., O'Connell, C. B., Luther, P. W., and Donnenberg, M. S. (1998). The EspB protein of enteropathogenic Escherichia coli is targeted to the cytoplasm of infected HeLa cells. Infect. Immun. 66, 5501-5507.

Thomas, D. R., Francis, N. R., Xu, C., and DeRosier, D. J. (2006). The threedimensional structure of the flagellar rotor from a clockwise-locked mutant of Salmonella enterica serovar Typhimurium. J. Bacteriol. 188, 7039-7048. doi: 10.1128/JB.00552-06

Thomas, N. A., Deng, W., Baker, N., Puente, J., and Finlay, B. B. (2007). Hierarchical delivery of an essential host colonization factor in enteropathogenic Escherichia coli. J. Biol. Chem. 282, 29634-29645. doi: 10.1074/jbc.M706019200

Thomas, N. A., Deng, W., Puente, J. L., Frey, E. A., Yip, C. K., Strynadka, N. C., et al. (2005). CesT is a multi-effector chaperone and recruitment factor required for the efficient type III secretion of both LEE- and non-LEE-encoded effectors of enteropathogenic Escherichia coli. Mol. Microbiol. 57, 1762-1779. doi: 10.1111/j.1365-2958.2005.04802.X

Thomassin, J. L., He, X., and Thomas, N. A. (2011). Role of EscU auto-cleavage in promoting type III effector translocation into host cells by enteropathogenic Escherichia coli. BMC Microbiol. 11:205. doi: 10.1186/1471-2180-11-205

Tobe, T., Beatson, S. A., Taniguchi, H., Abe, H., Bailey, C. M., Fivian, A., et al. (2006). An extensive repertoire of type III secretion effectors in Escherichia coli O157 and the role of lambdoid phages in their dissemination. Proc. Natl. Acad. Sci. U.S.A. 103, 14941-14946. doi: 10.1073/pnas.0604891103

Tobe, T., Schoolnik, G. K., Sohel, I., Bustamante, V. H., and Puente, J. L. (1996). Cloning and characterization of bfpTVW, genes required for the transcriptional activation of bfpA in enteropathogenic Escherichia coli. Mol. Microbiol. 21, 963-975.

Tomson, F. L., Viswanathan, V. K., Kanack, K. J., Kanteti, R. P., Straub, K. V., Menet, M., et al. (2005). Enteropathogenic Escherichia coli EspG disrupts microtubules and in conjunction with Orf3 enhances perturbation of the tight junction barrier. Mol. Microbiol. 56, 447-464. doi: 10.1111/j.13652958.2005.04571.x

Torruellas, J., Jackson, M. W., Pennock, J. W., and Plano, G. V. (2005). The Yersinia pestis type III secretion needle plays a role in the regulation of Yop secretion. Mol. Microbiol. 57, 1719-1733. doi: 10.1111/j.1365-2958.2005. 04790.x

Tree, J. J., Wolfson, E. B., Wang, D., Roe, A. J., and Gally, D. L. (2009). Controlling injection: regulation of type III secretion in enterohaemorrhagic Escherichia coli. Trends Microbiol. 17, 361-370. doi: 10.1016/j.tim.2009.06.001
Tsai, N. P., Wu, Y. C., Chen, J. W., Wu, C. F., Tzeng, C. M., and Syu, W. J. (2006), Multiple functions of 10036 in the regulation of the pathogenicity island of enterohaemorrhagic Escherichia coli O157:H7. Biochem. J. 393(Pt 2), 591-599. doi: 10.1042/BJ20051201

Ueno, T., Oosawa, K., and Aizawa, S. (1992). M ring, S ring and proximal rod of the flagellar basal body of Salmonella typhimurium are composed of subunits of a single protein, FliF. J. Mol. Biol. 227, 672-677.

Umanski, T., Rosenshine, I., and Friedberg, D. (2002). Thermoregulated expression of virulence genes in enteropathogenic Escherichia coli. Microbiology 148(Pt 9), 2735-2744. doi: 10.1099/00221287-148-9-2735

Vallance, B. A., and Finlay, B. B. (2000). Exploitation of host cells by enteropathogenic Escherichia coli. Proc. Natl. Acad. Sci. U.S.A. 97, 8799-8806. doi: 10.1073/pnas.97.16.8799

Vidal, J. E., and Navarro-Garcia, F. (2008). EspC translocation into epithelial cells by enteropathogenic Escherichia coli requires a concerted participation of type V and III secretion systems. Cell. Microbiol. 10, 1975-1986. doi: 10.1111/j.14625822.2008.01181.x

Vijayakumar, V., Santiago, A., Smith, R., Smith, M., Robins-Browne, R. M., Nataro, J. P., et al. (2014). Role of class 1 serine protease autotransporter in the pathogenesis of Citrobacter rodentium colitis. Infect. Immun. 82, 2626-2636. doi: 10.1128/IAI.01518-13

Viswanathan, V. K., Hodges, K., and Hecht, G. (2009). Enteric infection meets intestinal function: how bacterial pathogens cause diarrhoea. Nature Rev. Microbiol. 7, 110-119. doi: 10.1038/nrmicro2053

Wachter, C., Beinke, C., Mattes, M., and Schmidt, M. A. (1999). Insertion of EspD into epithelial target cell membranes by infecting enteropathogenic Escherichia coli. Mol. Microbiol. 31, 1695-1707.

Wagner, S., Königsmaier, L., Lara-Tejero, M., Lefebre, M., Marlovits, T. C., and Galán, J. E. (2010a). Organization and coordinated assembly of the type III secretion export apparatus. Proc. Natl. Acad. Sci. U.S.A. 107, 17745-17750. doi: $10.1073 /$ pnas. 1008053107

Wagner, S., Sorg, I., Degiacomi, M., Journet, L., Dal Peraro, M., and Cornelis, G. R. (2009). The helical content of the YscP molecular ruler determines the length of the Yersinia injectisome. Mol. Microbiol. 71, 692-701. doi: 10.1111/j.13652958.2008.06556.x

Wagner, S., Stenta, M., Metzger, L. C., Dal Peraro, M., and Cornelis, G. R. (2010b). Length control of the injectisome needle requires only one molecule of Yop secretion protein P (YscP). Proc. Natl. Acad. Sci. U.S.A. 107, 13860-13865. doi: 10.1073/pnas.1006985107

Wainwright, L. A., and Kaper, J. B. (1998). EspB and EspD require a specific chaperone for proper secretion from enteropathogenic Escherichia coli. Mol. Microbiol. 27, 1247-1260.

Wang, D., Roe, A. J., McAteer, S., Shipston, M. J., and Gally, D. L. (2008). Hierarchal type III secretion of translocators and effectors from Escherichia coli O157:H7 requires the carboxy terminus of SepL that binds to Tir. Mol. Microbiol. 69, 1499-1512. doi: 10.1111/j.1365-2958.2008.06377.x

Wang, Y. A., Yu, X., Yip, C., Strynadka, N. C., and Egelman, E. H. (2006). Structural polymorphism in bacterial EspA filaments revealed by cryo-EM and an improved approach to helical reconstruction. Structure 14, 1189-1196. doi: 10.1016/j.str.2006.05.018

Warawa, J., Finlay, B. B., and Kenny, B. (1999). Type III secretion-dependent hemolytic activity of enteropathogenic Escherichia coli. Infect Immun 67, 5538-5540.

Waters, R. C., O’Toole, P. W., and Ryan, K. A. (2007). The FliK protein and flagellar hook-length control. Protein Sci. 16, 769-780. doi: 10.1110/ps.07 2785407

Wee, D. H., and Hughes, K. T. (2015). Molecular ruler determines needle length for the Salmonella Spi-1 injectisome. Proc. Natl. Acad. Sci. U.S.A. 112, 4098-4103. doi: 10.1073/pnas.1423492112

Wiesand, U., Sorg, I., Amstutz, M., Wagner, S., van den Heuvel, J., Lührs, T., et al. (2009). Structure of the type III secretion recognition protein YscU from Yersinia enterocolitica. J. Mol. Biol. 385, 854-866. doi: 10.1016/j.jmb.2008.10.034

Williams, A. W., Yamaguchi, S., Togashi, F., Aizawa, S. I., Kawagishi, I., and Macnab, R. M. (1996). Mutations in fliK and flhB affecting flagellar hook and filament assembly in Salmonella typhimurium. J. Bacteriol. 178, 2960-2970.

Wilson, R. K., Shaw, R. K., Daniell, S., Knutton, S., and Frankel, G. (2001). Role of EscF, a putative needle complex protein, in the type III protein translocation 
system of enteropathogenic Escherichia coli. Cell. Microbiol. 3, 753-762. doi: 10.1046/j.1462-5822.2001.00159.x

Winardhi, R. S., Gulvady, R., Mellies, J. L., and Yan, J. (2014). Locus of enterocyte effacement-encoded regulator (Ler) of pathogenic Escherichia coli competes off histone-like nucleoid-structuring protein (H-NS) through noncooperative DNA binding. J. Biol. Chem. 289, 13739-13750. doi: 10.1074/jbc.M113. 545954

Wolff, C., Nisan, I., Hanski, E., Frankel, G., and Rosenshine, I. (1998). Protein translocation into host epithelial cells by infecting enteropathogenic Escherichia coli. Mol. Microbiol. 28, 143-155.

Wood, S. E., Jin, J., and Lloyd, S. A. (2008). YscP and YscU switch the substrate specificity of the Yersinia type III secretion system by regulating export of the inner rod protein YscI. J. Bacteriol. 190, 4252-4262. doi: 10.1128/JB.00328-08

Worrall, L. J., Vuckovic, M., and Strynadka, N. C. (2010). Crystal structure of the C-terminal domain of the Salmonella type III secretion system export apparatus protein InvA. Protein Sci. 19, 1091-1096. doi: 10.1002/pro.382

Xicohtencatl-Cortes, J., Monteiro-Neto, V., Ledesma, M. A., Jordan, D. M., Francetic, O., Kaper, J. B., et al. (2007). Intestinal adherence associated with type IV pili of enterohemorrhagic Escherichia coli O157:H7. J. Clin. Invest. 117, 3519-3529. doi: 10.1172/JCI30727

Yang, H., Shan, Z., Kim, J., Wu, W., Lian, W., Zeng, L., et al. (2007). Regulatory role of PopN and its interacting partners in type III secretion of Pseudomonas aeruginosa. J. Bacteriol. 189, 2599-2609. doi: 10.1128/JB.01680-06

Yang, J., Tauschek, M., Hart, E., Hartland, E. L., and Robins-Browne, R. M. (2010). Virulence regulation in Citrobacter rodentium: the art of timing. Microb. Biotechnol. 3, 259-268. doi: 10.1111/j.1751-7915.2009.00114.x

Yerushalmi, G., Litvak, Y., Gur-Arie, L., and Rosenshine, I. (2014). Dynamics of expression and maturation of the type III secretion system of enteropathogenic Escherichia coli. J. Bacteriol. 196, 2798-2806. doi: 10.1128/JB.00069-14

Yip, C. K., Finlay, B. B., and Strynadka, N. C. (2005a). Structural characterization of a type III secretion system filament protein in complex with its chaperone. Nat. Struct. Mol. Biol. 12, 75-81. doi: 10.1038/nsmb879

Yip, C. K., Kimbrough, T. G., Felise, H. B., Vuckovic, M., Thomas, N. A., Pfuetzner, R. A., et al. (2005b). Structural characterization of the molecular platform for type III secretion system assembly. Nature 435, 702-707. doi: 10.1038/nature03554

Younis, R., Bingle, L. E., Rollauer, S., Munera, D., Busby, S. J., Johnson, S., et al. (2010). SepL resembles an aberrant effector in binding to a class 1 type III secretion chaperone and carrying an $\mathrm{N}$-terminal secretion signal. J. Bacteriol. 192, 6093-6098. doi: 10.1128/JB.00760-10
Yu, X. J., Liu, M., Matthews, S., and Holden, D. W. (2011). Tandem translation generates a chaperone for the Salmonella type III secretion system protein SsaQ. J. Biol. Chem. 286, 36098-36107. doi: 10.1074/jbc.M111. 278663

Yu, X. J., McGourty, K., Liu, M., Unsworth, K. E., and Holden, D. W. (2010). pH sensing by intracellular Salmonella induces effector translocation. Science 328, 1040-1043. doi: 10.1126/science. 1189000

Zarivach, R., Deng, W., Vuckovic, M., Felise, H. B., Nguyen, H. V., Miller, S. I., et al. (2008). Structural analysis of the essential self-cleaving type III secretion proteins EscU and SpaS. Nature 453, 124-127. doi: 10.1038/nature06832

Zarivach, R., Vuckovic, M., Deng, W., Finlay, B. B., and Strynadka, N. C. (2007). Structural analysis of a prototypical ATPase from the type III secretion system. Nat. Struct. Mol. Biol. 14, 131-137. doi: 10.1038/nsmb1196

Zhao, R., Pathak, N., Jaffe, H., Reese, T. S., and Khan, S. (1996). FliN is a major structural protein of the C-ring in the Salmonella typhimurium flagellar basal body. J. Mol. Biol. 261, 195-208. doi: 10.1006/jmbi.1996.0452

Zhu, C., Feng, S., Thate, T. E., Kaper, J. B., and Boedeker, E. C. (2006). Towards a vaccine for attaching/effacing Escherichia coli: a LEE encoded regulator (ler) mutant of rabbit enteropathogenic Escherichia coli is attenuated, immunogenic, and protects rabbits from lethal challenge with the wild-type virulent strain. Vaccine 24, 3845-3855. doi: 10.1016/j.vaccine.2005.07.019

Zhu, K., González-Pedrajo, B., and Macnab, R. M. (2002). Interactions among membrane and soluble components of the flagellar export apparatus of Salmonella. Biochemistry 41, 9516-9524. doi: 10.1021/bi0203280

Zilkenat, S., Franz-Wachtel, M., Stierhof, Y. D., Galán, J. E., Macek, B., and Wagner, S. (2016). Determination of the stoichiometry of the complete bacterial type III secretion needle complex using a combined quantitative proteomic approach. Mol. Cell. Proteomics 15, 1598-1609. doi: 10.1074/mcp.M115.056598

Conflict of Interest Statement: The authors declare that the research was conducted in the absence of any commercial or financial relationships that could be construed as a potential conflict of interest.

Copyright (C) 2016 Gaytán, Martínez-Santos, Soto and González-Pedrajo. This is an open-access article distributed under the terms of the Creative Commons Attribution License (CC BY). The use, distribution or reproduction in other forums is permitted, provided the original author(s) or licensor are credited and that the original publication in this journal is cited, in accordance with accepted academic practice. No use, distribution or reproduction is permitted which does not comply with these terms. 